\title{
Las prácticas de control sobre los extranjeros en el virreinato del Río de la Plata (1730-1809)
}

\author{
por \\ Martin Biersack \\ Ludwig-Maximilians-Universität Múnich \\ martin.biersack@lrz.uni-muenchen.de
}

Durante el siglo XVIII la vigilancia de los extranjeros dependia fuertemente de la colaboración de los vecinos mediante la denuncia. Esta vigilancia informal, donde el gobierno solo actuaba en caso de conflictos, fue reemplazada a principios del siglo XIX por un control institucionalizado, permanente y clandestino. El artículo se basa en documentación del virreinato del Río de la Plata, tanto publicada como inédita del Archivo General de la Nación Argentina. Las fuentes más relevantes empleadas son reales cédulas, bandos y autos de gobierno, sobre todo los registros de extranjeros y las actas del Cabildo.

Palabras clave: Buenos Aires; Río de la Plata; extranjeros; siglo XVIII; régimen migratorio.

\section{INTRODUCCIÓN}

Las provincias del Río de la Plata, sobre todo su capital, Buenos Aires, tienen un interés especial para el análisis de los procesos migratorios en la América colonial tardía. Tuvieron un extraordinario crecimiento durante el siglo XVIII, y debido a su importancia para el comercio y a la cercanía con Brasil el número de extranjeros que vivían en Buenos Aires fue muy alto ${ }^{1}$. Emir Reitano supone que hacia finales del siglo XVIII había un 8,5\% de

\footnotetext{
${ }^{1}$ Brading, 1990: 94-97.
} 
extranjeros sobre un total de 45.000 habitantes. El mayor grupo fueron los portugueses, luego los italianos y los franceses ${ }^{2}$.

En general, para la América española, a pesar de que las leyes con solamente con pocas excepciones prohibían a los extranjeros la residencia ${ }^{3}$, el lugar de origen de una persona no era necesariamente relevante. Lo que importaba era la convivencia con los vecinos. Si un extranjero estaba integrado en la comunidad local se le consideraba vecino, y poco importaba entonces su origen extranjero. Este solo se volvía relevante en caso de conflictos ${ }^{4}$. Diversos conflictos con miembros de la sociedad local se sucedían porque se veían amenazadas la tranquilidad y la convivencia de la comunidad, sea por la actividad económica o la actitud religiosa, moral o política de los clasificados como extranjeros. Dichos conflictos se negociaba dentro de lo que se puede llamar el régimen migratorio: una esfera basada en leyes y normas donde varios actores con sus propios intereses intervienen para influir en el proceso migratorio ${ }^{5}$. El enfoque principal de este artículo para el análisis del régimen migratorio en el virreinato del Río de la Plata es la regulación de la migración por los actores gubernamentales. De acuerdo con Bert de Munck y Anne Winter se pregunta si los intentos de intensificar el control sobre el creciente número de extranjeros en el Buenos Aires colonial tardío llevaron a la expansión y profesionalización de las funciones de vigilancia y policiales modernas ${ }^{6}$. A menudo pasa desapercibido que fue precisamente el control de los migrantes lo que llevó a la construcción de una estructura estatal y que -sobre todo en el Estado-nación del siglo XIX- hizo posible distinguir entre los miembros de la propia nación y aquellos que se clasificaron como extranjeros ${ }^{7}$. En la Edad moderna eran los propios vecinos -sobre todo los representados en los Cabildos, la «élite capitular» ${ }^{8}$ - los que reclamaron la competencia en esta materia ${ }^{9}$. Como la disputaron con el poder Real hay que tener en cuenta un posible impacto de las reformas borbónicas, cuya preten-

${ }^{2}$ Reitano, 2010: 105-116. En el padrón de extranjeros de 1804, por ejemplo, se registró un total de 455 extranjeros: $57 \%$ eran portugueses, $22,1 \%$ italianos, $11,6 \%$ franceses y $4,7 \%$ ingleses.

${ }^{3}$ Véase: Konetzke, 1945: 269-299.

${ }^{4}$ Herzog, 2011: 31.

${ }^{5}$ Véase: Wolff, 2013: 1. Herzog, 2003: 205.

${ }^{6}$ Munck y Winter, 2012: 13.

7 Torpey, 2000: 6. Para el caso español véase también: Manz, 2006: 78.

${ }^{8}$ Laura Cristina del Valle designa con este término las principales familias de cuyos miembros se reclutó el Cabildo. Valle, 2014: 28.

${ }^{9}$ Herzog, 2006: 249. 
sión de aumentar el poder central y reducir la autoridad de las corporaciones debería haber influido en el régimen migratorio ${ }^{10}$.

Las fuentes más valiosas para el análisis planteado son las listas de expulsión y los padrones con los que el gobierno intentaba averiguar el número y la composición social de los extranjeros en la ciudad. Estas listas y registros han servido como base para numerosos estudios sobre los extranjeros en la América colonial española que sacaron conclusiones acerca de su composición social, sus trabajos y negocios, estado civil o pertenencia estamental ${ }^{11}$. En el presente artículo, no obstante, el interés no se centra en los extranjeros, sino en el funcionamiento de la administración, sobre todo las prácticas de control $\mathrm{y}$ el uso de paper technologies, los formatos de registro como tablas, listas y formularios con sus correspondientes categorías. Se analiza en qué medida influyeron en la construcción de la categoría del extranjero, su identificación y en la toma de decisión sobre su permanencia o su expulsión.

2. Prácticas para la regulación de la migración eXtranjera entre 1730 Y 1760

\section{Los bandos de gobierno}

La primera iniciativa durante el siglo XVIII para registrar a la población extranjera de Buenos Aires salió del Cabildo, cuyo procurador, en defensa de los intereses de los comerciantes locales, pedía en 1730 que el gobernador Bruno Mauricio de Zavala cumpliese la observancia de las leyes que prohibían a los extranjeros ejercer el comercio. Como su petición no tuvo el efecto deseado solicitó en 1732 la expulsión de todos los extranjeros de la ciudad ${ }^{12}$. Ser considerado extranjero podía, por lo tanto, no solamente restringir la actividad económica de un individuo, sino que hacía peligrar su permanencia en América. Pero la administración colonial lidiaba con el principal problema: cómo identificar a ciencia cierta a los extranjeros que vivían en los territorios bajo su mandato.

La medida más común para encontrar a los extranjeros era la publicación de un bando que les ordenaba presentarse ante las autoridades. Fue esta la la medida con la que el gobernador Zavala respondió a la petición del procurador. Publicó un bando en 1730 para convocar a todos los comerciantes

\footnotetext{
10 Sobre las reformas borbónicas y su impacto en América véase en general: Paquette, 2011.

11 Rodríguez Vicente, 1968. Campbell, 1972: 153-163. Gómez Pérez, 1980: 279-311. Yacou, 1982: 49-64. Lewis, 1984. Parrón Salas, 1998.

12 Acuerdos del Extinguido..., 1928: 242 y 551.
} 
extranjeros a la fortaleza donde fueran registrados, y otro en 1731 que esta vez convocó a todos los forasteros y extranjeros. Con los datos allí obtenidos por parte del gobierno se formó una lista que incluía los nombres de todos los que debían abandonar la ciudad porque no cumplían los requisitos necesarios para ser tolerados. Se quería expulsar a todos los protestantes y también a los extranjeros solteros que no ejercían oficios mecánicos. A pesar de las medidas adoptadas por el gobierno, parece que la orden de expulsión fue ignorada totalmente por parte de los extranjeros. Por esta razón el procurador del Cabildo demandó medidas más decididas del gobernador Bruno Mauricio de Zavala. Este, en cambio, se defendió alegando que además de haber repetido la orden de expulsión en 1732, no era por su propia desidia si muchos de los incluidos en la lista de expulsión no habían abandonado la ciudad, sino que se debía a la pasividad de la justicia ordinaria del Cabildo -alcaldes y alguacil-y de los ayudantes de la fortaleza a cuyo cargo estaba vigilar el cumplimiento de la expulsión ${ }^{13}$.

Con la presencia de los expulsados persistía para el gobierno el problema que significaba la permanencia de los extranjeros que provocaban conflictos con otros vecinos. La respuesta de los gobernadores fue la emisión de varios bandos de expulsión entre 1738 y 1743 . Como tampoco tuvieron efecto, el gobernador Domingo Ortiz de Rozas publicó en 1744 un bando mucho más severo que los anteriores. Alegó que los extranjeros tenían que abandonar la ciudad en sólo 15 días. Quienes fueran hallados después serían castigados con trabajo forzoso en la fortaleza de Montevideo. Además se amenazaba también a los porteños que dieran alojamiento a los extranjeros o los escondieran en sus casas con una multa de 225 pesos, de los cuales 25 se prometía al denunciante, y dos años de trabajo forzoso en Montevideo ${ }^{14}$. A pesar de la amenaza, ese bando tampoco parece haber impresionado mucho ni a los extranjeros ni a los porteños, ya que hasta 1750 casi anualmente se dictó un bando parecido y ninguno se cumplía, como constató el gobernador José de Andonaegui en 1748 porque a pesar de lo mandado sobre los extranjeros «se mantienen muchos en esta ciudad como en los partidos de su jurisdicción» ${ }^{15}$.

La implicación del Cabildo no se limitaba solamente a la vigilancia y la ejecución de órdenes gubernamentales. Tuvo un papel decisivo en la definición de la política migratoria, ya que consideró todos los asuntos de policía, desde el empedramiento de las calles, pasando por el control de precios de los

\footnotetext{
13 Ibidem: 556-558.

14 Archivo General de la Nación Argentina, Buenos Aires (AGNA), IX, Bandos, libro 1, fols. 36-38.

15 Ibidem, fol. 153 r.
} 
alimentos, hasta la vigilancia sobre la población como competencia suya, y tuvo mucho recelo en conservar o ampliar sus competencias frente a virreyes y gobernadores ${ }^{16}$. Muchos de los bandos emitidos por gobernadores y virreyes fueron contestados por el Cabildo o por su procurador que pedían una enmienda, sea para endurecer la política contra los extranjeros como sucedió en 1732, sea para ablandar una orden de expulsión demasiado dura y rígida. Esto sucedió entre 1738 y 1743, cuando el Cabildo en varias ocasiones se presentó ante el gobernador para pedir que este no expulsara a todos los extranjeros sin discriminación, como lo había mandado una Real Cédula del año 1736, sino que permitiera a los portugueses católicos y casados o a los que ejercían un oficio mecánico de utilidad, su permanencia en Buenos Aires ${ }^{17}$. La intervención del Cabildo para excluir de la expulsión a los oficios mecánicos útiles se repitió también en 1748. El gobernador había ordenado que todos los extranjeros solteros abandonaran la ciudad ${ }^{18}$. Los alcaldes ordinarios, antes de ejecutar la orden, pedían al gobernador que suspendiera el bando hasta que se realizase una lista con los oficios mecánicos y los labradores de campo que, por su utilidad, se debiera excluir de la expulsión. Para tal propósito se pidió listas de los gremios con los nombres de los maestros y oficiales extranjeros. En base a estas listas el Cabildo deliberó a quién se consideraba útil y, que por lo tanto, resultaba excluido de la expulsión. Esta información luego fue transmitida al gobernador. Según la lista del Cabildo, los sujetos considerados útiles fueron dos carpinteros ingleses, un tornero, un botonero y un cirujano portugueses, dos peluqueros franceses y un herrero genovés ${ }^{19}$. Cuando en enero de 1750 un sastre portugués presentó una petición en el Cabildo para ser excluido de la expulsión por la utilidad de su oficio, el Cabildo se la concedió también ${ }^{20}$.

\section{La vigilancia vecinal}

¿Qué se puede deducir de la publicación periódica y repetida de los bandos? Uno tiende a pensar en su poca efectividad. Si se hubiera cumplido lo mandado, rara vez hubiera existido la necesidad de publicar al menos una vez al año un bando de expulsión. Pero la repetición de los bandos no debe ser solamente

\footnotetext{
16 Lynch, 1955: 347-362.

17 Acuerdos del Extinguido..., 1929: 470-473; 1930: 151-155. Tau Anzoátegui, 1982: 276-279.

${ }_{18}$ AGNA, IX, Bandos, libro 1, fols. 153-154.

19 Acuerdos del Extinguido..., 1931: 338-342 y 359-360.

${ }^{20}$ Ibidem: 541.
} 
interpretada como un fracaso de las medidas dictadas, más bien las prácticas de gobierno por bandos requerían su publicación periódica. Aunque los principios legales de la política migratoria estaban prescritos por las Leyes de Indias, su aplicación concreta en el contexto local de Buenos Aires fue resultado de la colaboración entre el Cabildo y el gobernador. Ambas instituciones intervenían en la formulación de bandos y de los criterios según los cuales los extranjeros podían ser tolerados o no. Pero en la práctica ni el gobierno controlaba el cumplimiento de los bandos o de los muy concretos autos de expulsión, ni la justicia del Cabildo - que tenía este encargo- contaba con los dispositivos o el personal para llevarlo a cabo. El papel de la vigilancia lo ocupaban los mismos vecinos. La publicación de bandos y el subsiguiente control vecinal se parecían al método utilizado por la inquisición con los edictos de fe que incluía igualmente la exhortación a los vecinos de denunciar las infracciones. Los vecinos tenían en sus manos el poder de cubrir los extranjeros o de denunciarlos cada vez que se publicaba un bando que animaba a la población a la denuncia. Una ordenanza legal y global contra los extranjeros se volvía así personal e informal, y se dirigía solamente contra aquellos que, de alguna forma, causaban problemas a sus vecinos ${ }^{21}$.

El sistema de control vecinal daba cierta protección a los extranjeros integrados, pero siempre dependían de la buena voluntad de sus vecinos, y estos no en todos los casos la tenían. Los mercaderes de Buenos Aires se veían amenazados por la competencia que les causó la presencia de muchos comerciantes extranjeros en el puerto. Sobre todo los portugueses, por sus relaciones con Brasil y el supuesto contrabando, ponían en peligro el monopolio de comercio con España ${ }^{22}$. Estos mercaderes extranjeros quizá estaban bien integrados y algunos casados, con lo cual los bandos de expulsión no les habrían afectado hasta entonces. Por lo tanto, y refiriéndose a la prohibición para extranjeros de abrir una tienda o pulpería, el 7 de junio 1749 los mercaderes «españoles legítimos naturales, vecinos residentes» en Buenos Aires formaron una junta en la que otorgaron un poder judicial a Francisco Antonio de Riva el cual le concedía plenas facultades para representarlos legalmente ante la audiencia y el gobernador para conseguir el cumplimiento de las leyes; esto es: la expulsión de todos los comerciantes extranjeros ${ }^{23}$. Riva alegó ante el gobernador

${ }^{21}$ Según Tamar Herzog la diferenciación entre extranjeros y naturales se tomaba desde abajo, desde los propios vecinos. Cabildo y autoridad real solo intervenían si los miembros de la comunidad no consiguieron resolver los conflictos causados por los extranjeros. Herzog, 2003: 204.

${ }^{22}$ Tejerina, 2004: 56-62.

${ }^{23}$ Mercaderes extranjeros. Sobre su expulsión, AGNA, IX, 39-7-3, exp. 7, fols. 1r-2r. Véase también: Kraselsky, 2010: 87. 
la cantidad de extranjeros que habían llegado con los barcos de registro a la ciudad, que estos no solamente se habían adueñado del comercio dentro de la urbe y con la provincia, sino también del intercambio comercial con Chile y Perú, en grave perjuicio a los vecinos naturales de Buenos Aires ${ }^{24}$.

El gobernador no podía ignorar estas quejas que tenían un claro fundamento legal y pidió una lista de los extranjeros con tienda o pulpería en la ciudad. Con esta petición el gobierno dejaba la decisión sobre quiénes deberían abandonar la ciudad en manos de los vecinos. No hacía falta actuar de forma global contra los extranjeros, bastaba expulsar a los que perturbaron los intereses de una parte influyente de los vecinos que se sentían perjudicados por su permanencia en Buenos Aires, o sea, los comerciantes. Estos brindaban la información sobre sus competidores que vivían en su ciudad y les hacían -indebidamente- competencia. Riva le entregó al gobernador una lista con los nombres de 41 extranjeros que tenían tienda en Buenos Aires, con indicaciones sobre su ubicación y el estado civil de sus dueños, así como del lugar de su procedencia. En total, 22 de los comerciantes extranjeros eran portugueses, 15 genoveses, 2 franceses y 1 inglés. El gobernador aceptó la lista sin disputa, pero excluyó a los extranjeros casados de la expulsión, mandando que los solteros cerraran sus tiendas en un plazo de 15 días y abandonaran la ciudad en el plazo de un mes ${ }^{25}$.

\section{Los padrones y las listas de expulsión}

Las representaciones de los vecinos o las corporaciones no solamente actuaron como denunciantes contra los extranjeros. Fueron las propias autoridades coloniales las que, en determinadas oportunidades, pedían la colaboración de los consulados o los gremios para averiguar la presencia extranjera en una ciudad, pidiéndoles listas con informaciones específicas. En Perú, el Virrey Amat, para cumplir con una real orden que mandaba registrar a todos los extranjeros que vivían bajo su mando, tuvo que recurrir en 1768 al Consulado de Lima $^{26}$. En España fueron los consulados de los extranjeros las instituciones que en muchos casos proporcionaron las listas que se mandaron hacer a partir de $1764^{27}$. En Buenos Aires se requería en 1748 una lista de los gremios que incluía los nombres de los maestros y los oficiales extranjeros, y en 1749 el

\footnotetext{
${ }^{24}$ Mercaderes extranjeros. Sobre su expulsión, AGNA, IX, 39-7-3, exp. 7, fol. 7r.

${ }^{25}$ Ibidem, fols. 9-10.

${ }^{26}$ Campbell, 1972: 156.

27 Manz, 2006: 110.
} 
gobernador pedía la mencionada lista de los comerciantes extranjeros a la representación de los comerciantes naturales.

No obstante, la manera más usual de formar un padrón de extranjeros completo -hay que suponer que los consulados o gremios conocían sobre todo a sus compañeros extranjeros- era convocarlos mediante la publicación de un bando, como había sucedido en Buenos Aires en 1731. Debido a que el registro de los extranjeros aún no era continuo, se tenía que repetir tal procedimiento cada vez que las autoridades veían necesario «tener una visión exacta» ${ }^{28}$ de los extranjeros. Hay constancia de que durante la primera mitad del siglo XVIII, además del año 1731, el gobernador mandó en 1734 al Cabildo hacer un padrón de todos los habitantes, en el cual se diferenciara entre vecinos, extranjeros y vagabundos, y otro en 1738 para cumplir una Real Cédula que mandaba expulsar a todos los extranjeros de América ${ }^{29}$.

Tanto los padrones de extranjeros como las listas de expulsión eran un instrumento activo para la regulación de la población extranjera que servían para determinar quién era extranjero y quién no ${ }^{30}$. Para ser identificado como extranjero había dos posibilidades: o los propios extranjeros se autoconsideraron así y se presentaron ante las autoridades cuando fueron convocados mediante la publicación de un bando, o los vecinos o sus corporaciones denunciaron a un miembro de la comunidad como extranjero. La administración colonial disponía hasta finales de la centuria de muy limitados instrumentos para identificar y encontrar a los extranjeros. Dependían, principalmente, de la colaboración de los vecinos o de la voluntad de los propios extranjeros.

$\mathrm{Si}$ alguien estaba incluido en un padrón de extranjeros se le asignaba aquel status con todos los problemas que esto podría conllevar en América. No era una determinación inocente -según Tamar Herzog- diferenciar entre extranjeros y naturales, y tampoco era evidente. Lo que hoy en día parece una práctica clara y poco problemática, fue muy distinta en la Edad moderna. No era una cuestión abstracta, binómia, que permitía una decisión clara. Era un continuum, donde había un amplio margen de posibilidades, entre individuos totalmente extranjeros y totalmente naturales, según los criterios que se aplicaban en cada caso. Hubo algunos criterios objetivos como el lugar de nacimiento o la ascendencia, pero eso no hacía a un individuo automática-

${ }^{28}$ Bando del 3. 2. 1765, AGNA, IX, Bandos, libro 3, fol. 21.

29 Para 1738: "Padrones de la Ciudad y Campaña de Buenos Aires", Documentos para la Hist..., 1919. Lamentablemente de estos tres padrones sólo sabemos que se registró a los extranjeros en 1731 y 1738, pero desconocemos por completo su contenido. Respecto a 1734 desconocemos si realmente se ejecutó lo ordenado por el gobernador.

30 Manz, 2006: 109-110. 
mente un extranjero. Si pretendía ser español bastaba ser considerado como como tal por los vecinos, y poco importaba si sus padres fueran extranjeros o si hubiera nacido en otro país si su comportamiento no daba lugar a dudas en torno a su naturaleza española ${ }^{31}$.

Los problemas de identificación a ciencia cierta de un extranjero ocurrieron también en la lista de expulsión que los mercaderes de Buenos Aires habían fabricado en 1749. Algunos de los incluidos en la lista protestaron contra la expulsión, alegando que eran españoles y, por lo tanto, tenían el derecho de permanecer en Buenos Aires. Las autoridades se veían ahora ante la necesidad de comprobar su identidad. Los métodos de identificación por parte de las autoridades fueron complicados por las estrategias de camuflaje por parte de los extranjeros, ya que era algo común entre los aquellos hacerse pasar por españoles para no llamar la atención de vecinos o autoridades. La hispanización del propio apellido o la adopción de un apellido español totalmente nuevo eran una práctica muy común. Como no existía ninguna institución que prescribiera o controlara la permanencia de un apellido, no existía obstáculo para cambiarlo ${ }^{32}$. Además del camuflaje, como estrategia de parte de los foráneos, fue la propia diversidad de los naturales españoles la que dificultó la identificación de los extranjeros. Cuando el rey ordenó al Consulado y a la Aduana Real de Lima que intensificaran el control de los barcos para impedir el arribo de extranjeros que viajaban sin licencia, el Virrey Amat aceptó esta orden, pero alegó las serias dificultades para distinguir los extranjeros de los españoles ${ }^{33}$. Para las autoridades era muy difícil diferenciar un navarro, un catalán, un vasco o un gallego, a ciencia cierta, de un francés o un portugués ${ }^{34}$.

En casos de duda muchas veces se recurría a testigos, pero los testimonios de aquellos no siempre sirvieron para aclarar con certeza la naturaleza de un individuo ${ }^{35}$. De los supuestos extranjeros incluidos en la lista de expulsión en 1749, Fernando Arentavegaray, según él mismo «nativo del reino de Navarra de padres conocidos y vasallos de su Magestad», buscó disipar las dudas acerca de su origen mediante la presentación de tres testigos. Estos confirmaron todo lo dicho por su amigo, al que habían conocido cuando vivían en Cádiz. El representante de los comerciantes españoles se daba por satisfecho con estos testimonios y tachó a Arentavegaray de la lista. Menos

${ }^{31}$ Herzog, 2011: 26-31.

32 Sánchez Rubio y Testón Núñez, 2008: 213-239.

33 Campbell, 1972: 155.

34 Véase para este aspecto: Poggio Ghilarducci, 2011: 187-188.

35 Otras pruebas consistían en el nombre de un individuo, su aspecto físico, la ropa o la lengua. A veces se alegaron también rumores que cursaron en el público acerca de la verdadera naturaleza de una persona. Herzog, 2003: 113. 
suerte tuvo Juan Bautista Cacho, supuestamente oriundo de Málaga, dueño de una peluquería en Buenos Aires y casado con María Rita Fragela. Como no había nombrado testigos para verificar su reclamo, se determinó que tenía que cerrar su tienda y volver con su mujer a Europa. Las autoridades no se molestaron en hablar personalmente con el supuesto andaluz, algo que quizá hubiera podido aclarar su origen ${ }^{36}$.

También hubo algunos extranjeros que protestaron contra la expulsión por otras razones. La decisión de cómo proceder en estos casos fue delegada por el gobernador al representante de los comerciantes, Riva. El dueño de una tienda de ropa, el portugués Juan Luis Salgado, se defendía alegando que en su tienda vendía ropa de barcos de los registro, un argumento que Riva rechazó. Más bien reclamó ante el gobernador que, por la presencia de mercaderes portugueses como Salgado se extraviaba «todo el dinero para la Colonia, Geneiro y Lisboa se enriquece aquel reino, empobreciéndose este, y el de Europa». Exigió entonces nuevamente la expulsión de todos los extranjeros ilegales, basándose en las Leyes de Indias, de las que ningún juez debía desviarse. También sentenciaba que el gobernador debía guardar lo que el Rey manda y llevar a cabo el auto de expulsión ${ }^{37}$.

A pesar de todo el empeño de Riva y lo decretado por el gobernador, la mayoría de las tiendas de los extranjeros, incluso la de Salgado, siguió abierta y sus dueños permanecieron en la ciudad. Gabriel de Terán, apoderado de los comerciantes españoles, habló por esta inobediencia de una «extranjera rebeldía» y exigió en dos súplicas un «vigilante celo» de parte del gobernador y la aplicación de los severos castigos previstos contra los ilegales, sobre todo la confiscación de sus bienes. Como consecuencia, el gobernador encargó a su teniente general la ejecución de la expulsión, pero esta medida tampoco tuvo el efecto deseado, ya que Terán en una tercera súplica informó que «hasta el presente se ha retardado y prosiguen los extranjeros en la continuación de sus ventas» ${ }^{38}$.

Cuando el gobernador a finales de 1749 ordenó a la justicia del Cabildo efectuar una visita de las pulperías agregó que en esta ocasión también "se averiguará los extranjeros solteros que se alteren con tiendas, tendejones, o pulperías y se les notificará que dentro de ocho días salgan de esta ciudad» ${ }^{39}$. Es el primer indicio de que las autoridades -en este caso el Cabildo que era

${ }^{36}$ Mercaderes extranjeros. Sobre su expulsión, AGNA, IX, 39-7-3, exp. 7, fols. 24r-27v y $31 \mathrm{r}-32 \mathrm{v}$. No está claro porque se quería expulsar en este caso a un hombre casado.

37 Ibidem, fols. 13r-16r.

38 Ibidem, fols. 19r-22r.

39 Bando del 18. 11. 1749, Archivo Histórico Nacional, Madrid (AHN), IX, Bandos, libro 1, fols, 263-265. 
el encargado de la visitación- controlaran sistemáticamente el cumplimiento de una orden de expulsión. Parece que al final los mercaderes españoles consiguieron su propósito y la mayoría de los comerciantes extranjeros fueron expulsados, porque en la visita por Francisco Merlo solamente fueron encontrados dos extranjeros que se habían quedado ilegalmente en la ciudad: el genovés Blas Duarte y el inglés Juan Inglés. A estos se mandó abandonar la ciudad en un plazo de ocho días ${ }^{40}$. No obstante, los severos castigos que iban a caer sobre los que no cumplían las órdenes de expulsión, y que cada bando repetía fielmente, parece que nunca fueron aplicados. Otro indicio de que la mayoría de los comerciantes extranjeros realmente había abandonado la ciudad es que a partir de esta fecha hasta la década de los setenta ya no se encuentran más quejas por parte de los mercaderes españoles.

Los padrones de extranjeros, aparte de diferenciar de forma clara entre extranjeros y naturales, tuvieron, además, otra finalidad. El hecho de ser extranjero ponía a un individuo ante el peligro de ser expulsado, pero no necesariamente tenía que ser así. Tanto las leyes como la práctica gubernamental excluían a aquellos que cumplieran con ciertos criterios. Así que los padrones eran también una herramienta para la toma de decisión del gobierno o del Cabildo con respecto a quiénes se podía tolerar y a quien no, y como la decisión se basaba en determinados criterios, se requería la información correspondiente en el registro, por ejemplo, la procedencia, su tiempo de permanencia en la ciudad, la razón de aquella, su ocupación o profesión, y su estado civil ${ }^{41}$. También la lista de 1749 contenía información acerca del extranjero aparte de su naturaleza, para justificar su expulsión. Era, sobre todo, su ocupación como comerciantes, ya que para estos la permanencia en un puerto de Indias estaba repetidamente prohibida. Además informaron acerca de su estado civil, porque aquellos que estaban casados con una hija del país se solían tolerar.

Es posible que los comerciantes de Buenos Aires como también los de otros puertos hubieran hecho sus representaciones ante las Casa de Contratación. Esta elevó en 1749 un informe al Consejo de Indias, que se hacía eco de las protestas sobre la presencia de comerciantes extranjeros en los puertos de América. El resultado del informe fue una real orden de enero y una real cédula de febrero de 1750 en las cuales todos los gobernadores y virreyes de

${ }^{40}$ Mercaderes extranjeros. Sobre su expulsión, AGNA, IX, 39-7-3, exp. 7, fol. 34r. Cabe suponer también que los visitadores del Cabildo no estaban conformes con las pretensiones de los mercaderes y quizá cubrían a los extranjeros, sobre todo a los menos visibles como los portugueses.

${ }^{41}$ Estos criterios reflejan los que se requería para obtener una carta de naturaleza del Consejo de Indias. Véase Herzog, 1997: 251. 
América fueron instados a expulsar a todos los extranjeros ilegítimos de los territorios de su jurisdicción ${ }^{42}$.

Además de complacer a los intereses comerciales de los grandes mercaderes españoles parece que detrás de las Reales Cédulas de los años 1750, 1753 y 1755 se hallaba también un interés fiscal de la propia Corona. Se ordenaba, en consonancia con las leyes, expulsar a todos los extranjeros, salvo a quienes tuvieran oficios mecánicos o a los que estaban casados con naturales. La Corona quería con esta medida aumentar la presión sobre los extranjeros tolerables para que estos legalizaran su estatus, solicitando una carta de naturaleza o la composición, algo que traía ingresos para el fisco real ${ }^{43}$. El gobernador de Buenos Aires tenía que tasar cuánto debían abonar, según sus posibilidades, cada extranjero casado para ser finalmente tolerado. Aparentemente, José de Andonaegui, para cumplir con lo mandado, fue demasiado lejos, ya que le extrañó mucho al rey enterarse que su gobernador tomó

...el medio de recurrir al ordinario eclesiástico, para que no concediese licencia de contraer matrimonio a los dichos extranjeros, que hallándose apremiados a su salida, se valían de este refugio para quedarse ahi, y pedís se os ordene en esta inteligencia lo que debeis practicar en adelante en casos de esta calidad [...] advirtiéndoos finalmente la extrañeza que ha causado ${ }^{44}$.

Concluye la Real Cédula que cualquier persona debe casarse con la libertad que le convenga, advirtiendo al gobernador no mezclarse «en materia que no os toca, ni pertenece» ${ }^{45}$.

\section{El CONTROL DE LOS EXTRANJeros ENTRE 1760 y 1800}

La llegada al trono español de Carlos III (1759-1788) influyó de forma directa también a los extranjeros, cuya situación estaba cambiando. El programa de reformas borbónicas incluyó una restricción en torno a los privilegios de los que, muchos de ellos, gozaban en España ${ }^{46}$. En relación con los extranjeros en América, donde no gozaban de privilegios como en la península, es

42 Gómez Pérez, 1980: 285-287.

${ }_{43}$ Para Nueva España: Poggio Ghilarducci, 2011: 193.

${ }^{44}$ Documentos para la Hist..., 1915, doc. 81: 375-380.

45 Idem.

${ }^{46}$ Recio Morales y Glesener, 2011: 13-14. 
desconocido si las reformas tuvieron algún impacto sobre su situación ${ }^{47}$. En Buenos Aires, por lo menos, no se encuentra ningún bando que ordenara la expulsión generalizada de los extranjeros después de 1755 hasta finalizar el siglo, aunque si llegaron Reales Cédulas que la exigieron ${ }^{48}$.

\section{Registro e internación}

La actividad gubernamental contra los extranjeros cobró un nuevo pulso durante los años sesenta a causa de un cambio en el marco político: el 12 de diciembre de 1761 se anuló el Tratado de Madrid con lo cual el conflicto entre España y Portugal sobre el dominio del Río de la Plata volvió a estar a la orden del día. Los extranjeros de las naciones enemigas, Portugal y su principal aliado Inglaterra, se convirtieron ahora en un problema de seguridad. A finales de 1761 el gobernador Pedro de Cevallos publicó un bando que dio la orden a todos los extranjeros de presentarse dentro del plazo de 15 días ante el Comandante de Infantería Nicolás de Elorduy, para su registro. En vez de ordenar la expulsión de los extranjeros, algo que era habitual en bandos anteriores, el gobernador prefirió alegar la real clemencia, porque $\mathrm{Su}$ Majestad «tiene conferida al gobierno de esta provincial facultad de indultar a los extranjeros, en quienes concurran las calidades y circunstancias que las leyes previenen con tal que se solicite su real confirmación se previene que pueden ocurrir así las personas que pretendieren esta gracia» ${ }^{49}$. Además del padrón de extranjeros del año 1761 se ordenaron registros generales o parciales de las «naciones enemigas» en 1763, 1765 y $1771^{50}$. La expulsión de los extranjeros ya no era un tema ${ }^{51}$.

Dichos registros en muchos casos servían como base para la internación de extranjeros. Esta medida se aplicaba para impedir que en tiempos de guerra

47 Konetzke hace referencia de tres expulsiones de extranjeros durante el reinado de Carlos III, en los años 1767, 1779 y 1785. Konetzke, 1945: 28.

${ }^{48}$ Real Cédula del 10. 5. 1761 para el Virrey del Perú y Real Cédula del 15. 9. 1776, recordándo que en la provincia se cumplan enteramente las cedulas insertas sobre expulsion de extranjeros de 1750 y de 1753, AGNA, IX, Catálogo cronológico de Reales Cédulas, Provisiones y Decretos, vol. 18, fols. 117-119r. Documentos para la Hist.., 1915, doc. 81: 375-380. En 1785 llegó una Real Orden para expulsar a todos los extranjeros, Archivo General de Indias, Sevilla (AGI), Indiferente, 801. Solicitud de una carta de naturaleza por el francés Francisco Daraux (4. 2. 1789).

49 Bando del 10.10.1761, AHN, IX, Bandos, libro 2, fols. 281-282.

${ }^{50}$ AGNA, IX, Bandos, libro 2, fol. 355 y libro 3, fols. 21 y 198.

${ }^{51}$ Véase también: Sidy, 2011: 405. 
aquellos que viviesen cerca de la costa entraran en contacto con el enemigo, con lo cual fueron enviados a ciudades que estuvieran ajenas a cualquier influencia de parte de las potencias enemigas, pero dejándoles la puerta abierta para su vuelta ${ }^{52}$. Así sucedió durante el conflicto con Inglaterra y Portugal entre 1761 y 1765 , cuando se deportaron a los miembros de las naciones enemigas temporalmente a las provincias del interior ${ }^{53}$. Lo mismo sucedió cuando surgió un nuevo conflicto con Inglaterra a causa de la Guerra de Independencia de Estados Unidos. En enero de 1780 se publicó una orden real según la cual todos los ingleses tenían que retirarse a Mendoza o a Córdoba mientras durara la guerra ${ }^{54}$.

Quizá por la mayor tolerancia del gobierno superior el discurso contra los extranjeros en el Cabildo se endureció durante los años sesenta y setenta. Correspondió a los intereses económicos del grupo más influyente en Buenos Aires, los grandes mercaderes españoles, el grupo con mayor peso en el Cabildo, sobre todo a partir de mediados del siglo XVIII ${ }^{55}$. En defensa de sus intereses pretendían expulsar a sus competidores en el comercio legal y extra legal: los portugueses. Este ciclo culminó en 1776 en un arduo ataque contra el gobernador Vertiz por su pasividad ante el peligro y el daño que, a los ojos del Cabildo, causaba la presencia de tantos extranjeros en Buenos Aires. La voluntad del Cabildo de tomar medidas fue muy urgente porque «todos estos extranjeros que hay en esta ciudad en un número muy considerable pervierten la buena fe y verdad del comercio y de aquí nace la infinidad de demandas, quejas y recursos, y el tener los jueces empleada la atención y el tiempo en ellos ${ }^{56}$. Pero como el gobernador Vertiz no quería expulsar a los extranjeros, los cabildantes informaron al Rey quien efectivamente mandó una Real Cédula al Cabildo y al gobernador recordándoles en febrero de 1777 el cumplimiento exacto de las Leyes de Indias ${ }^{57}$.

A pesar de las amonestaciones Reales, el gobernador y posterior virrey parece haber acatado pero no cumplido, ya que no se conoce ningún bando que anunciara medidas de control o expulsión contra los extranjeros. Aun así, estas protestas contra los extranjeros fueron las últimas del siglo XVIII que se encuentran en las actas del Cabildo. Cesa a partir de la creación del virreinato del Río de la Plata el discurso contra los extranjeros. Pueden haber

\footnotetext{
52 Para esta práctica en el Río de la Plata véase: Tejerina, 2012: 49-78.

53 Dos bandos de febrero de 1765, AGNA, IX, Bandos, libro 3, fols. 63-65.

${ }^{54}$ AGNA, IX, 31-3-6, exp. 183.

${ }^{55}$ Valle, 2014: 71-78. Socolow, 1991: 141.

${ }^{56}$ Acuerdos del Extinguido..., 1928: 496.

57 Ibidem: 765 y 497-498. Para la Real Cédula véase nota 48.
} 
sido cuatro los factores que influyeron en esta relajación: la instalación del virreinato en Buenos Aires en 1777, la conquista de La Colonia del Sacramento durante el mismo año, el decreto de libre comercio en 1778 y la guerra de España contra Inglaterra de 1779 y 1783. Estando Colonia en manos españolas y con la presencia de un virrey en Buenos Aires, el contrabando disminuyó notablemente. La apertura de los puertos coloniales al comercio libre lo hacía además, menos atractivo, ya que se abrían ahora, rutas legales alternativas. El puerto de Buenos Aires vivía su época dorada y transitaba un crecimiento extraordinario, sobre todo del comercio de los grandes mercaderes con $\mathrm{Cádiz}^{58}$. No obstante, surgieron nuevos inconvenientes. Durante la guerra contra Inglaterra el tráfico directo con Cádiz se veía comprometido. Los comerciantes porteños, ante la amenaza de la superioridad naval británica, recurrieron a la intermediación de los portugueses en Brasil para llevar adelante el tráfico con España. Los comerciantes portugueses que durante buena parte del siglo XVIII fueron considerados una amenaza para la élite porteña se convirtieron durante la Guerra de los siete años y la Guerra de independencia estadounidense en sus colaboradores, un hecho que aumentó notablemente la presencia lusitana en el puerto ${ }^{59}$. Devuelta la paz, el Cabildo tampoco tenía motivo para quejarse por la presencia extranjera en el puerto. A partir de 1783 gobernó el Marqués de Loreto en Buenos Aires quien intentó poner fin al contrabando y al comercio con los extranjeros ${ }^{60}$. A diferencia de Vertiz, sí expulsaba regularmente a extranjeros a España ${ }^{61}$.

\section{En pos de un registro continuo de la población}

El interés por conocer la composición extranjera de las ciudades no estaba limitado a los casos de guerra. Más bien existía una voluntad generalizado de parte del gobierno por adquirir información acerca de la composición

58 Brown, 2002: 62-74.

59 Tejerina, 2004: 72-82.

60 Ibidem: 87-88.

61 Las expulsiones de Loreto no comprendían solamente a extranjeros sino «342 personas que después de su posesión en este mando hasta fin del año 1786 ha hecho despachar a España por casados ausentes de sus mujeres, polizones, y marineros desertores, extranjeros, y eclesiásticos extranjeros en cumplimiento de la Real Instrucción de Gobierno que le fue encomendado», AGI, Buenos Aires, 38. Indice de la correspondencia de virreyes, 1787, n. 639. Véase también la Relación de los casados, extranjeros, polizones e intrusos de los dominios de Portugal que se condujeron en la Barca Santa Amalia que comprendía cinco extranjeros, AGI, Buenos Aires, 38. Comunicación de virreyes, 1788, n. 11. 
poblacional de sus dominios. Disponer de censos era una clave de la gubernamentalidad, con lo cual a lo largo de la centurua se intensificaron en todo el mundo hispano las actividades que pretendían registrar a la población. Dentro de esta linea el ministro Gálvez ordenó en 1776 un padrón para los territorios ultramarinos españoles con el objetivo de instalar a partir de aquel año un continuo registro de la población «con la debida distinción de clases, estados y castas de todas las personas de ambos sexos, sin excluir los párvulos y que [...] al fin de cada uno se haya de anotar el aumento, o disminución, que hubiese cada año» ${ }^{62}$. En 1777 llegó la Real Orden de Gálvez a Buenos Aires. El Cabildo designó para la elaboración del padrón una comisión que en 1778 registró a toda la población, tanto de la ciudad como de la campaña. A fin de actualizarlo anualmente, Diego de Salas a cargo interinamente del gobierno, encargó a los alcaldes de barrio hacer cada año un padrón de sus respectivos barrios $^{63}$. Esta orden, no obstante, parece que solo fue cumplida una vez, en 1779. Si bien la institución de los alcaldes de barrio por estas fechas estaba lejos de funcionar con regularidad tampoco hubo otros funcionarios que se hubieran hecho cargo de un mandado que pronto cayó en olvido.

El padrón de 1778 reflejaba distintas categorías socio-raciales y diferenciaba entre españoles, indios, pardos, mulatos, y negros ${ }^{64}$. Los extranjeros de Buenos Aires se subsumaban a los españoles que, por lo tanto, representaban la población blanca de origen europeo en su conjunto. En el padrón de la ciudad de 1779 se introdujo la categoría «naturaleza». Con esta categoría se podría diferenciar a los españoles de los extranjeros, porque informaba del lugar de nacimiento de un individuo. En las listas de los alcaldes de barrio se encuentran tanto las distintas regiones de España o de América, como países extranjeros, ciudades importantes como Londres o Madrid, y también el lugar de nacimiento de muchos de los esclavos negros: «Congo» o «Angola». Los hijos de inmigrantes, si habían nacido en la ciudad, se convertían automáticamente en porteños ${ }^{65}$.

62 Pérez y Montoya Guzmán, 2010: 23.

63 "Padrones de la Ciudad y Campaña de Buenos Aires", Documentos para la Hist..., 1919: 71-87.

${ }^{64}$ Era también el caso de otros censos que se fabricaron en 1778, por ejemplo el de Nueva Granada. Véase: Solano, 2014: 1-59.

${ }^{65}$ AGNA, IX, 99-7-6, Padrones de 1778 y de 1779. En total se contaba 415 extranjeros: 289 portugueses $(69,6 \%), 63$ italianos $(15,2 \%), 45$ franceses $(10,8 \%), 9$ alemanes $(2,1 \%)$ y 7 británicos $(1,6 \%)$. El número de los extranjeros no está completo porque algunos alcaldes de barrio no notaron a los que vivían en sus barrios. Por ejemplo seguía el alcalde del barrio nueve, Joseph Gómez, quien ya en 1778 había registrado la población de su barrio, con los 
Los padrones de la campaña llevados a cabo por los alcaldes de la Hermandad en 1778 y 1779 en cambio, no introdujeron el criterio de la nacionalidad. Solamente se diferenciaba los forasteros de los vecinos. Según el «método para la formación del padrón» se entendía por forastero «el que no tuviere su muger en la jurisdicción; pues que todo el que la tuviere, aunque sea uno y otro forastero se deben reputar por vecinos $\gg{ }^{66}$. La integración en la comunidad, visible a partir del matrimonio, lo convertía en un vecino con todos los deberes y derechos. Mientras un bonaerense casado en Montevideo era considerado forastero, un nativo de Río de Janeiro que estaba casado en el lugar era considerado vecino, y ambos se subsumía bajo la categoría «españoles». Aparentemente, ser de origen extranjero importaba menos aún en el campo que en la ciudad.

El afán por tener informaciones más exactas sobre la población cobró un nuevo impulso durante los años de la Revolución francesa. A fin de conseguirlas el virrey Arredondo, en un intento de instituir los alcaldes de barrio nuevamente -algo que ya había intentado sin éxito su antecesor Vertiz- dio en enero de 1794 instrucciones en las que les encargó el continuo registro de los vecinos de sus barrios ${ }^{67}$. Asimismo tenían la obligación de informar al superior gobierno continuamente sobre la presencia de forasteros y hacer una matrícula de los extranjeros de sus barrios, distinguiendo los últimos en domiciliarios y transeúntes. Al parecer no fue tan fácil para el virrey encargar un registro continuo de la población, ya que en 1798 virrey Olaguer lo solicitó nuevamente, esta vez al Cabildo. Pero este se negó alegando carecer de personal y medios para llevar a cabo un padrón ${ }^{68}$. Es, por lo tanto, bastante probable que durante todo el siglo XVIII la confección de un registro de la población en general, y el de la extranjera en particular, fuera algo excepcional, lejos de realizarse en forma periódica ${ }^{69}$.

mismos criterios socio-raciales, con lo cual en su registro no aparece ningún extranjero, ya que estos se subsumaban a los españoles.

${ }^{66}$ AGNA, IX, 99-7-6, Método para la formación del padrón, fol. 2r.

${ }^{67}$ El resultado de esta instrucción podría haber sido el padrón de Buenos Aires de 1794, en: AGNA, IX, 9-7-4.

68 "Padrones de la Ciudad y Campaña de Buenos Aires", Documentos para la Hist..., 1919: 101-113. En Nueva Granada se encargo en 1793 igualmente el registro de los extranjeros a los alcaldes de barrio. García Estrada, 2012: 84.

${ }^{69}$ Un último intento en esta dirección lo ordenó el virrey Cisneros en 1809. Encargó a los alcaldes de barrio, además de registrar a toda la población, dejar constancia específica de todos los extranjeros que vivían en sus barrios. "Padrones de la Ciudad y Campaña de Buenos Aires", Documentos para la Hist..., 1919: 120-129. 


\section{El impacto de la Revolución francesa}

Debido al temor a la difusión de las ideas de la Revolución francesa el Rey mandó en 1791 levantar una matrícula de todos los extranjeros en España ${ }^{70}$. En 1793 se emitió una Real provisión para expulsar a todos los franceses no domiciliados ${ }^{71}$. No hay noticias que se confeccionara en América ni la matrícula de 1791, ni tampoco que se efectuara la orden de expulsión de franceses transeúntes de 1793. Fue en 1795 cuando alertado por las noticias sobre la dispersión de ideas subversivas en América, el Rey daba aviso a los virreyes y a los gobernadores de vigilar con máxima alerta a los franceses residentes en América, castigar a los sediciosos y remitir a los sospechosos a España, concibiendo así mismo a los vecinos como «el principal resorte para arrojarlos [franceses sediciosos] de esos dominios» encargándoles de velar por el buen orden de las cosas y denunciar cualquier francés sospechoso ${ }^{72}$.

En Perú, el Virrey Francisco Gil de Taboada y Lemos mandó hacer secretamente una lista de todos los franceses residentes en Lima y, de todos los europeos que habían llegado desde 1790. Su investigación sobre la presencia de ideas sediciosas en la ciudad finalmente llevó a la expulsión de dos franceses que en 1795 fueron remetidos a España ${ }^{73}$. Más decidido actuó el virrey Branciforte en México, donde la vigilancia de los franceses fue exhaustiva ${ }^{74}$. Se procedió contra varios de ellos sospechando que fueran partidarios de la revolución. De los 138 franceses registrados en el virreinato, 68 fueron enviados finalmente a Cádiz ${ }^{75}$.

A diferencia de México y Lima, en Buenos Aires no se conoce ningún censo de los extranjeros en general o de los franceses en especial que se hubiera confeccionado en contestación a la orden Real. Los alcaldes de barrio, el instrumento que estaba pensado para velar sobre la tranquilidad pública, no funcionó hasta principios del siglo XIX con regularidad. Tampoco se conoce ningún registro o bando de expulsión generalizada contra los franceses como en México. Parece que en el Río de la Plata no se adoptó esta medida, y la vigilancia gubernamental -tomando en este punto la Real orden al pie de la letra- se centró en la vigilancia vecinal de los franceses mediante la denuncia. Le ventaja para tal procedimiento era que los franceses que no llamaron la

\footnotetext{
70 Ozanam, 1990: 215-227.

71 González Beltrán, 1997: 108.

72 Real Orden, 22.5.1795, Archivo del Museo Mitre, Buenos Aires, caja 29, pieza 1, nº 21 .

${ }^{73}$ Rosas Lauro, 2006: 145-149.

74 Enríquez Macías, 1990: 715-728.

${ }^{75}$ Langue, 1989: 223-232.
} 
atención y vivían de forma tranquila con sus vecinos estaban libres de persecución. La desventaja era que la denuncia daba lugar a falsas acusaciones, como sucedió en 1795 con la denominada «conspiración de los franceses» ${ }^{76}$.

A principios de 1795 circularon rumores en la población sobre una supuesta sublevación de los franceses. Aparecieron pasquines difamatorios, y se presentaron falsas denuncias que, finalmente, se convirtieron en una especie de caza de brujas contra los franceses. El virrey, alertado por los rumores, encargó en febrero de 1795 una investigación exhaustiva al Alcalde de primer voto, Martín de Alzaga, quien arrestó a treinta personas sospechosas, entre ellos nueve franceses. En este ambiente tenso y poco favorable uno de los presos franceses, el panadero Luis Dumont, había tomado ya precauciones, escondiendo sus bienes, porque «temía lo echasen por ser francés y estar la nación en guerra con España, como acaeció con los portugueses y le pareció se los habían de quitar» ${ }^{77}$. Otro preso, el sardo Polovio, sabía perfectamente que solo le habían encarcelado porque «fuese conceptuándolo francés», y «se corría la voz que los negros y franceses querían levantarse» ${ }^{78}$ Alzaga sometió a los sospechosos a varios interrogatorios en los cuales llegó a aplicar hasta el tormento. No obstante, no se encontró culpa alguna en los acusados extranjeros, salvo la de residir sin licencia en América con lo cual la sentencia final de la Audiencia de Buenos Aires resultó en su expulsión bajo partida de registro ${ }^{79}$. Sin embargo, la expulsión nunca se concretó, ya que los imputados se encontraban aún en Buenos Aires en los años siguientes.

\section{LA INTENSIFICACIÓN DE LAS PRÁCTICAS DE CONTROL (1801-1809)}

Registro y expulsión de los extranjeros 1801-1805

En 1801, cuando España se enfrentó con Portugal en la Guerra de las Naranjas, hubo en el Río de la Plata incursiones portuguesas en la banda oriental que contaron, según la opinión de los vecinos de la campaña, con el apoyo de los portugueses residentes allí. Para remediar esta situación, los hacendados y destacados miembros de la milicia de esta zona mandaron peticiones al vi-

${ }^{76}$ Sobre este acontecimiento véase: Ortega, 1947. Lewin, 1960: 9-57. Johnson, 2002: 259-277; 2013: 203-238.

77 Ortega, 1947: 119.

78 AHGN, IX, 36-1-5, exp. 6, fol. 32r.

${ }^{79}$ Una vez firmada la paz de Basilea con Francia, el embajador francés intervino a favor de los súbditos franceses encarcelados en Buenos Aires. Archivo del Museo Mitre, Buenos Aires, caja 29, pieza 1, no 21 a. 
rrey reclamando la expulsión de todos los portugueses. Los consideraron un grave peligro para la seguridad de los colonos y para todo el virreinato, ya que los responsabilizaron de los saqueos y los robos a los que fue sometido el territorio fronterizo con Brasil de la banda oriental. El contrabando de los portugueses perjudicaría, además, el erario Real y el comercio de los naturales. En consecuencia, el virrey Joaquín del Pino, ordenó la internación de todos los portugueses de la campaña oriental del Río de la Plata ${ }^{80}$. Además publicó en diciembre de 1801 un bando en Buenos Aires que mandó a los portugueses a registrarse ante los alcaldes de barrio e indicarles el camino que pensaban tomar para dirigirse «precisamente en lo más interior de esta banda del río, y a distancia por ahora de doce leguas» ${ }^{81}$.

El fin de las hostilidades no mejoró mucho la situación para los portugueses. Debido al declive del comercio con España por el bloqueo británico a partir de 1797 y a la necesidad comercial de buscar vías alternativas con colonias neutrales, había aumentado notablemente la presencia de comerciantes extranjeros en Buenos Aires ${ }^{82}$. Nuevamente los portugueses sirvieron de intermediarios en fases de la guerra con Gran Bretaña, cuando el comercio directo con la península estaba dificultado. Con la paz de Amiens entre España y Gran Bretaña en 1802 los monopolistas españoles vieron la posibilidad de volver al tráfico exclusivo con la península. Los comerciantes lusos pasaron de ser colaboradores necesarios a competidores. Quizá a espaldas del virrey los comerciantes porteños movieron hilos en Madrid para presionarle hacia una política más decidida contra los extranjeros, ya que en 1803 le fue recordado por medio de una Real Cédula del Consejo de Indias que todas las instituciones y autoridades en América debían colaborar para expulsar a los

\footnotetext{
${ }^{80}$ Exp. iniciado ante el Exmo Señor Virrey de estas provincias por varios vecinos hacendados de esta banda oriental del Río de la Plata, solicitando el extrañamiento y expulsión de los portugueses intrusos y poblados en estas campañas, AGNA, IX, 30-6-8, exp. 3. Debería haber tenido poco efecto la medida del virrey, ya que los vecinos de la banda oriental repitieron a principios de 1802 , con mucha vehemencia, su petición para la expulsión de los portugueses -probablemente otra vez sin éxito, porque en el registro de extranjeros de 1804 se encontraban todavía muchos portugueses tanto en la campaña como en la ciudad de Montevideo. Sobre expulsión de extranjeros a virtud de carta acordada del Supremo Consejo de Indias, AGNA, IX, 35-03-06, exp. 3, fol. 2r. (a partir de ahora citado como: Sobre expulsión de extranjeros...), fols. 39-41.

${ }^{81}$ AGNA, IX, Bandos, libro 8, fols. 74-75.

82 Según un informe que Pedro Cerviño redactó en 1806 por encargo del Cabildo bonaerense para el Consejo de Indias la presencia de los extranjeros en Buenos Aires subió notablemente durante el gobierno del marqués de Avilés. Torre Revello, 1946: 86, nota 2. El mismo marqués de Avilés se mostró también favorable para poblar la frontera del norte con familias portuguesas. Tejerina, 2012: 69-70.
} 
extranjeros. Además de esta amonestación le llegó al virrey una denuncia desde las provincias del interior, donde un sujeto anónimo había acusado a un grupo de ingleses de divulgar allí ideas «libertinas» y protestantes. A consecuencia, el virrey mandó una circular a los gobiernos de las provincias del interior para que registraran a todos los extranjeros ${ }^{83}$.

No obstante, el resultado del registro en el interior no contentó a las autoridades de la capital. Al parecer la orden del virrey había sido poco clara. Los gobernadores de las provincias mandaron al virrey solamente los nombres de 15 ingleses o norteamericanos y enfatizaron su rectitud moral y religiosa, debido a que el virrey había justificado el registro con apoyado en rumores a este respecto, pero sus informes contenían pocos datos más. Sólo de Salta y Mendoza llegaron informaciones acerca de -supuestamente- todos los extranjeros que allí vivían ${ }^{84}$. Los datos no permitieron a los encargados del gobierno, hacerse una imagen completa de la presencia extranjera en las provincias, tanto en relación a su número exacto como a su modo de vida. Imposible tomar con este registro fragmentario una decisión sobre quién tendría que abandonar el virreinato y quién podría quedarse.

Un expediente de la Audiencia de Buenos Aires, hecho por el fiscal José Márquez de la Plata, aconsejó al nuevo virrey Sobremonte mandar una segunda circular «en que se ordene a los gobernadores comandantes y justicias que tomando a su cuidado la remisión de extranjeros a esta capital», se excluya solamente a aquellos que posean oficios útiles y de buenas costumbres. Todos los demás extranjeros debían ser expulsados en caso de no tener licencia Real porque, como alegó el fiscal, la ley no contenía margen de interpretación ${ }^{85}$.

${ }^{83}$ Circular del 12.10.1803 en: Sobre expulsión de extranjeros... AGNA, IX, 35-03-06, exp. 3, fols. 1-2r. Carta acordada del superior consejo, Madrid, 20.4.1803, ibidem, fols. 23-24r. La Real orden iba acompañada del aviso que se negaba la carta de naturaleza al comerciante portugués Joaquín Dacosta y Bastos porque no presentaba los requisitos necesarios y, siendo extranjero, le estaba prohibido el comercio en Indias. El rey encargó al virrey la observancia de las leyes que, en el caso de Dacosta, significaría la confiscación de bienes y la expulsión de América. Dacosta entonces vivía ya más de veinte años en el Río de la Plata, donde había desempeñado cargos como el de oficial primero de la administración de Misiones. A pesar de la amonestación real no se le expulsaba, ya que figura todavía en el padrón de 1804. Documentos para la Hist..., 1919: 180. Sobre su persona véase además: Tejerina, 2012: 38-39. Probablemente fue por sus actividades mercantiles un blanco de los monopolistas españoles, la razón por la cual intentó legitimar su situación ante el Consejo de Indias. Quizá porque no estaba casado este le denegó esta gracia.

${ }^{84}$ Que eran cuatro en el primer caso y seis en el segundo.

${ }^{85}$ Expediente del 20.8.1804, en: Sobre expulsión de extranjeros..., AGNA, IX, 35-03-06, exp. 3, fol. 25 . 
La visión de Márquez de la Plata era la de un jurista que decidía según el tenor de la ley. Pero en la práctica gubernamental se tuvieron en cuenta, aparte de la ley, otras normativas ${ }^{86}$. Una era la costumbre, según la cual se toleraban a los bien integrados, a los que se consideraba vecinos. El problema para el gobierno superior en Buenos Aires consistía ahora en que había que definir criterios que hicieran mensurable esta integración. Una práctica social se convirtió así en un procedimiento burocrático con la necesidad de criterios formales para decidir quiénes de los extranjeros eran vecinos y podían por lo tanto, ser tolerados. Sobremonte quería tolerar como vecinos a los extranjeros que vivieran, por lo menos, desde hacía diez años en el país y estuvieran casados; o a aquellos que estuvieran casados con una nativa y tuvieran hijos o nietos. Esta excepción se aplicaría solamente a los extranjeros que vivían en las provincias del interior, porque en los puertos marítimos -Buenos Aires y Montevideo- la tolerancia era menor debido a la competencia que allí significaban para los comerciantes nativos. Aun así el virrey añadió que se podía también excluir de la expulsión a otros extranjeros que estuvieran en «alguna circunstancia que exija el que sean tratados con otra consideración». La última disposición daba al virrey justamente un marco interpretativo por encima de la ley que el Márquez de la Plata le había negado. Quizá Sobremonte no estaba seguro respecto a cómo sería recibido su procedimiento, ya que solicitó al Consejo de Indias la aprobación de sus medidas ${ }^{87}$.

Los criterios utilidad, buenas costumbres y integración que Márquez de la Plata y Sobremonte definían para la tolerancia de los extranjeros se tradujeron en criterios según los cuales los extranjeros debían ser registrados ante los alcaldes de barrio de sus ciudades. Los bandos que fueron publicados en Buenos Aires y en las provincias requerían datos sobre religión, profesión, ocupación, origen, estado civil y bienes raíces y/o muebles con los que el gobierno superior pensó obtener la información suficiente para decidir si un extranjero cumplía o no con los requisitos necesarios para permanecer en Indias $^{88}$. Obviamente, no se pensaba averiguar nada acerca de las costumbres de los extranjeros, y con la fijación de estos criterios para el registro tampoco se podía obtener información sobre la duración del matrimonio de los extranjeros y si estos tuvieran hijos o nietos.

86 Tau Anzoátegui, 1992: 512-529.

87 Sobre expulsión de extranjeros... AGNA, IX, 35-03-06, exp. 3, fols. 25v-27v. Es llamativo que Sobremonte no consideró explícitamente el servicio en la milicia como indicador para la integración social. En la práctica era una forma muy convincente para evitar una orden de expulsión. Véase Tejerina, 1997: 139.

${ }_{88}$ Circular del 3.10.1804, AGNA, IX, 35-03-06, exp. 3, fols. 25v-27v. Bando del 8.10.804, AGNA, Bandos, libro 8, fols. 218-219. 
A finales de 1804 los alcaldes de barrio mandaron sus informes al gobierno, alegando que seguían averiguando si se hallaba algún extranjero escondido en sus respectivos barrios. El caso del protomédico irlandés Gorman demuestra que el control funcionaba. El alcalde Goicoolca sabía que tres mujeres inglesas vivían en su casa, pero el protomédico prefirió no registrarlas y, cuando Goicoolca visitó su casa y preguntó explícitamente por ellas negó su presencia. Pero el alcalde siguió con su pesquisa y consiguió la confirmación de su sospecha. Cuando al salir de la casa se cruzó con un mozo de Gorman este confirmó la presencia de las mujeres inglesas, al igual que los vecinos del protomédico, a cuyas casas acudió el alcalde posteriormente. Consecuentemente, Goicoolca inscribió a las tres mujeres inglesas en la lista de los extranjeros de su barrio ${ }^{89}$.

La mayoría de los informes cumplieron con los criterios prescritos y daba información bastante detallada sobre los bienes y la ocupación de los extranjeros. Solamente el alcalde del barrio 8 redactó una tabla, con lo cual la información que brindó sobre los distintos extranjeros era muy reducida, contestando cada criterio de manera escueta. Tampoco señaló determinados datos relevantes para medir la integración social de un extranjero como su servicio en la milicia, una información que los demás alcaldes sí habían brindado a pesar de que no estaba prescrita por el bando. El alcalde de barrio 6 daba, además del informe, un esquema de su barrio donde marcaba el domicilio exacto de cada extranjero ${ }^{90}$.

En octubre de 1804 el virrey había creado una comisión a cargo del oidor de la Real Audiencia Joaquín Bernardo de Campurano para tomar una decisión, en base a los informes de los alcaldes de barrio, sobre quiénes de los extranjeros tenían que abandonar Buenos Aires ${ }^{91}$. La comisión y el virrey, quizá por falta de información acerca de la duración del matrimonio, amplió los criterios y todos los casados fueron excluidos de la expulsión. Por lo tanto, la aserción de Sobremonte en cuanto a que la expulsión de los extranjeros se efectuó según el más estricto cumplimiento de los criterios prescritos por el Consejo de Indias del 23 de abril de 1803 solo era verdad parcialmente. Se decidió expulsar a 126 de un total de 455 extranjeros. Entre ellos se contaban los los protestantes, los reformados y al único anglicano que se hallaba en el territorio, así como a los solteros que no ejercían un oficio útil ${ }^{92}$.

\footnotetext{
${ }^{89}$ Documentos para la Hist..., 1919: 183-184.

90 Ibidem: 121-191.

${ }_{91}$ Sobre expulsión de extranjeros... AGNA, IX, 35-03-06, exp. 3, fol. 29.

${ }_{92}$ Documentos para la Hist..., 1919: 191-196.
} 
El aviso de expulsión fue remitido a los afectados por los alcaldes de barrio. Se les mandaba embarcarse hacia Europa en la siguiente ocasión que se presentara, bajo amenaza de severos castigos. Era de suponer que, como los alcaldes de barrio conocían bien el domicilio de los extranjeros, la expulsión se efectuara sin muchos problemas. La realidad fue otra. La exactitud burocrática del procedimiento chocó en este punto con las circunstancias de una ciudad abierta como Buenos Aires, donde los extranjeros sin mayores problemas podían escaparse de la expulsión. Se refugiaron en el campo, se embarcaron hacia otros puertos americanos, o, simplemente, cambiaron de barrio y desaparecieron así de la vista ${ }^{93}$. Los alcaldes de barrio consiguieron transmitir solamente a una tercera parte de los afectados el mero aviso de expulsión. Algunos de estos protestaron contra tal medida. El angloamericano Juan Coou de Boston y el sueco Xaime Badal, por ejemplo, fueron finalmente tolerados porque se habían ya convertido del protestantismo al catolicismo. Al fabricante de guitarras portugués Antonio Quiros, soltero, se le concedió el permiso por su servicio en la milicia, su avanzada edad y además, por la utilidad de su oficio $^{94}$. Finalmente el oidor Juan Bazo y Berry como comisionado para la expulsión de los extranjeros se resignó ante los hechos, quejándose sobre los muchos recursos que los extranjeros presentaron al virrey con lo que dilataron su expulsión, así como sobre «la ayuda ineficaz de unos brazos poco activos y diligentes la que son en la mayor parte los de los alcaldes de barrio». Recomendó al virrey únicamente la salida inmediata de los mercaderes extranjeros y de todos los protestantes porque en sus casos las leyes no concedían la menor indulgencia. Con respeto a los demás extranjeros quiso, para el momento, practicar tolerancia hasta que se mejorara la situación, ya que los extranjeros pobres no les era posible pagar un viaje a Europa, y la expulsión de los demás extranjeros con recursos para viajar era difícil por falta de barcos, y tampoco era urgente, porque sus ocupaciones no eran perjudiciales ${ }^{95}$.

Ya en el verano de 1804 había llegado un primer informe desde Montevideo. El fiscal Márquez de la Plata, quien había recibido el encargo de revisar los datos que llegaban desde las provincias, entendió que el mismo resultaba insuficiente para tomar una decisión de acuerdo a los criterios establecidos por el virrey. Dicho informe en forma de lista abarcaba a 140 extranjeros

93 Ibidem: 200-202.

94 Ibidem: 203-210.

95 Exp. de Juan Bazo y Berry, AGNA, Tribules Criminal, 1a serie, legajo B, n. 1. Con el alcalde del barrio 5, José Pereira Lucena, por ejemplo, fue curiosamente un portugués el encargado de registrar a los extranjeros de ese cuartel. Reitano, 2006-2007: 128. Si su condición de extranjero influyó en el registro y la verificación de la expulsión solo se puede especular. 
agrupados según el distrito en el que vivían. Aquellos extranjeros que servían en la milicia fueron consignados en un listado aparte. Muy probablemente, en Montevideo, el registro se había realizado con anterioridad a la llegada de la circular desde Buenos Aires debido a que la lista estaba elaborada según los criterios: nombre, tiempo de residencia, estado civil y ocupación, faltando información sobre la religión y la profesión que Sobremonte había establecido como criterios a consignar. Con estos datos insuficientes el fiscal no se atrevía a formular una regla general para la expulsión, no obstante, como gran parte de los listados no cumplía ninguno de los criterios de excepción, estimó forzoso su remisión a la capital ${ }^{96}$. Nuevamente el virrey, se mostraba menos estricto que el fiscal, negándose a proceder hacia la expulsión para lo que alegó que era mejor esperar a la llegada de los informes provenientes de las demás provincias ${ }^{97}$.

Entre enero y abril de 1805 fueron llegando dichos informes al gobierno en Buenos Aires. A diferencia de Buenos Aires, donde la cercanía de los barrios habría garantizado una cierta uniformidad, los informes de las provincias variaron mucho en forma, extensión e incluso en los criterios que se aplicaron. Es llamativo el empeño de algunos gobernadores en defender a los extranjeros de su provincia, por ejemplo en Mendoza, donde fueron registrados 108 extranjeros, de los cuales 98 eran portugueses. La mayoría había sido enviada allí como prisioneros de guerra luego de la retoma de Colonia de Sacramento en 1778. El virrey Cevallos les había dado a 200 de aquellos el permiso para quedarse si así lo querían ${ }^{98}$. Llevaban muchos años en la provincia, la mayoría estaba casado con naturales y tenía hijos y nietos. A pesar de no figurar como uno de los criterios señalados por el virrey, en Mendoza se informó también respecto a la avanzada edad de determinados portugueses. El comandante de armas, quien redactó el informe, concluyó con un parecer personal que, a su entender, los extranjeros de su provincia «no comprehenden la calidad de los que deben ser retirados de estos dominios $\rangle^{99}$.

Santa Fe mandó una tabla en la que se consignaron 36 extranjeros, hecha en base a los criterios prescritos. Por su parte, Corrientes realizó una lista de 24 extranjeros. Muy corta y de escaso contenido es la lista de los cuatro extranjeros que mandó La Paz. El gobernador de Salta, en cambio, se empeñó en brindar información muy detallada acerca de los ocho extranjeros que

\footnotetext{
96 Relación que manifiesta el número de extranjeros que se han introducido en el distrito, Sobre expulsión de extranjeros... AGNA, IX, 35-03-06, exp. 3, fols. 39-41.

${ }^{97}$ Ibidem, fols. $44 \mathrm{v}-45 \mathrm{r}$.

98 Tejerina, 2012: 58-59.

99 Sobre expulsión de extranjeros... AGNA, IX, 35-03-06, exp. 3, sin folio.
} 
vivían bajo su mando, aportando documentos que probaban las declaraciones de los registrados. Cada expediente fue acompañado, además, de un parecer del fiscal. Con este procedimiento el gobernador de Salta quería convencer al gobierno superior de que todos los extranjeros fueran excluidos de la expulsión, porque no solamente daba pruebas de su lealtad por el rey de España, algunos habían donado repetidas veces dinero durante la guerra, sino que también describía su religiosidad ejemplar o la utilidad de sus oficios. El informe avanzaba más allá de unos nombres y unos criterios anónimos, permitiendo ver a los individuos como el niño francés Juan Federico Moran de doce años, huérfano, que servía en casa de un español o como el genovés Felipe Ruiz Reynoso, quien ejercía como el único boticario en la provincia, y por lo tanto resultaba de imprescindible utilidad, además de ser consignado como buen católico y de buenas costumbres. Tuvo éxito el procedimiento del gobernador, y en todos los casos el virrey consintió en la permanencia de los extranjeros en la provincia ${ }^{100}$.

En el conjunto de informes los gobernadores pidieron en varias oportunidades que se realizacen excepciones a la expulsión, pero en ningún caso solicitaron la remoción de un individuo. De hecho, no se ha conservado un documento que indicara si al final se expulsó a extranjeros de las provincias del interior. Eso se debe en buena parte a los esfuerzos de los gobernadores de defender a los extranjeros con informes muy detallados. Cuanta más información se diera de las características de los sujetos en cuestión más difícil resultaba llevar a cabo la expulsión ${ }^{101}$. También razones pragmáticas podrían haber movido al gobierno superior en Buenos Aires a una posición tolerante. En las provincias faltaba mano de obra. A excepción de la gran cantidad de exprisioneros de guerra portugueses en Mendoza, muy pocos extranjeros vivían en el interior. La expulsión de estos no habría parecido ni necesaria ni útil.

\section{La revisión de los métodos de registro en 1807}

El muy limitado éxito de la expulsión del año 1805 derivó en dos demandas: una de parte del Cabildo y otra proveniente del Consulado de Buenos Aires en aquel mismo año. En ellas solicitaban vehementemente al virrey

100 Ibidem, sin folio.

101 Según Tamar Herzog a quien se temía era el extranjero abstracto contra cuya presencia se daba las órdenes de expulsión con cierta liberalidad, «pero a la hora de formularlas -en efecto, a la hora de concretarlas en personas particulares- esta claridad se desvanecía». Herzog, 2006: 249. 
la expulsión de los extranjeros por el daño que estos, según lo que creían, causaban al Estado y a la religión. El Consulado, además, denunciaba que el comercio de los naturales se veía perjudicado por la presencia de tantos extranjeros ${ }^{102}$. El Cabildo, en cambio, incorporó a su protesta el peligro para la seguridad que en tiempos de guerra significaba la permanencia de tantos ingleses en la ciudad ${ }^{103}$. Fue un tiempo convulso. La guerra con Inglaterra, cuya superioridad naval hizo casi imposible el comercio directo entre Buenos Aires y España, afectó gravemente a la ciudad. El comercio con neutrales, sobre todo con Brasil, en los que participaron muchos extranjeros, se convirtió más que nunca en una necesidad para el virreinato. El gobierno de los virreyes, a pesar de la prohibición legal, toleró estas prácticas porque eran vitales, tanto para abastecer la demanda del virreinato con productos extranjeros, como para poder exportar los propios productos ${ }^{104}$. Por lo tanto no tenían mucho interés en expulsar a los extranjeros.

Sobremonte tenía, además, otra razón para ignorar las demandas del Cabildo. Durante todo el siglo XVIII el ayuntamiento quería tomar parte activa en la decisión en torno a quiénes de los extranjeros podían ser tolerados, y a quiénes había que expulsar. Sin embargo a partir de la instalación del virreinato y la sanción real de 1778 no aparecieron más demandas del Cabildo en torno a la regulación de la migración. Estas reaparecieron con Sobremonte quien como virrey -más que sus sucesores- defendía la autoridad Real, manifiesta en su persona, sobre las pretensiones del Cabildo para extender su influencia y poder ${ }^{105}$. Consecuentemente consideró también la política migratoria como prerrogativa Real que correspondía al virrey y a la Audiencia, pero no al Cabildo. Es significativo que instaló comisiones a cargo de los jueces de la Audiencia para el registro y la expulsión de los extranjeros, pero prescindía totalmente de la colaboración del Cabildo que sí durante el siglo XVIII había tenido protagonismo en estos asuntos. La presencia de tantos extranjeros fue ahora una circunstancia que el Cabildo aprovechó al máximo para demostrar que el virrey no cumplía con sus deberes de buen gobernante, y posteriormente se justificó su destitución, entre otras cosas, por su permisividad con los extranjeros ${ }^{106}$.

102 "Representación del Consulado de Buenos Aires al Virrey Sobremonte, 16.3.1805", De Studer, 1958: 350-354.

103 “Acuerdo del Cabildo del 17.5.1805”, Acuerdos del Extinguido..., 1926: 86.

104 Tjarks y Vidaurreta, 1962: 5.

105 Valle, 2006: 23-46.

106 Pedro Cerviño explicó en un informe del Cabildo destinado al Consejo de Indias que la causa de la pérdida temporal de la ciudad fue el permiso que se había dado a los extranjeros de venir en estos territorios y dedicarse al comercio. Archivo General de la República Argen- 
Con la ausencia de Sobremonte a raíz de la primera invasión inglesa no disminuyó la presión del Cabildo. Aplicó un nuevo instrumento para conseguir su propósito y legitimarlo ante el vacío de poder: la opinión del pueblo y de los vecinos. En septiembre de 1806 se leyó en el Cabildo una petición de vecinos y comerciantes que solicitaba la expulsión de los extranjeros y el cese del comercio con aquellos considerados neutrales ${ }^{107}$. El Cabildo apoyó esta petición y subrayó de nuevo los daños que la practicada tolerancia causaba para la monarquía ${ }^{108}$. Su atención se dirigía hacia los ingleses, los irlandeses y los angloamericanos, quienes, por la guerra, eran percibidos como un enemigo dentro de la propia ciudad. La Real Audiencia, que llevaba temporalmente el gobierno superior cedió ante la presión del Cabildo y ordenó su internación en las provincias del interior. Para llevarla a cabo se nombró al oidor Juan Bazo y Berry «como especialmente encargado de esta comisión, y los alcaldes de barrio podrán contribuir a que se realice» ${ }^{109}$.

Con la conquista de Montevideo el 3 de febrero de 1807 se preveía en Buenos Aires un nuevo ataque, con lo cual se tomaron medidas para garantizar la seguridad de la ciudad. Una de estas medidas concernió a los extranjeros. En marzo, el Cabildo y la Audiencia encargaron a los alcaldes de barrio que registraran a los extranjeros de sus barrios, aplicando los mismos criterios que ya se habían utilizado en 1804. Por la prisa del registro -se temía un inminente ataque inglés- los veinte informes que llegaron a la Audiencia eran muy esquemáticos y no siempre contenían los datos requeridos. Aumentó también el número de tablas, que ahora fueron tres ${ }^{110}$. Parece que la internación del año 1806 no había tenido mucho efecto, ya que nuevamente, y en base a los informes, la Audiencia mandó que todos los portugueses que no estaban alistados para defender la patria, así como todos los ingleses y angloamericanos, deberían presentarse ante los alcaldes ordinarios, donde les sería notificado que abandonaran la ciudad dentro de tres días para su internamiento. Pero

tina..., 1889: 210-211. Sobremonte, en cambio, se defendió en una carta a Godoy, alegando que sí había intentado expulsar a los extranjeros, pero que este mal estaba tan arraigado que sus medidas no habían tenido ningún efecto. "Carta de Sobremonte al Príncipe de la Paz" del 14. de julio 1806 , ibidem: $87-88$, nota 2 .

107 Las representaciones de vecinos y comerciantes correspondían en gran parte con la élite capitular, con lo cual la congruencia de intereses para nada es sorprendente. Probablemente, como supone Laura Cristina del Valle, el propio Cabildo organizó estas demandas para instrumentalizarlas. Valle, 2014: 268-270. Sobre las «voces del pueblo» en América en general véase: Guerra, 2002: 359-360. Sobre el uso por parte del Cabildo de peticiones de vecinos y demandas del pueblo las páginas de del Valle citadas arriba.

108 Acuerdos del Extinguido..., 1926: 312-313.

109 Ibidem: 315-319.

110 Documentos para la Hist..., 1919: 213-247. 
al contrario de lo que tanto el Consulado como el Cabildo habían exigido durante meses, la Audiencia no veía necesario actuar contra los demás extranjeros de la ciudad, ya que no había razones para su expulsión ${ }^{111}$. No tuvo en consideración las leyes contra los extranjeros, lo único que importaba en aquel momento a la Audiencia eran cuestiones de seguridad.

Pero esta tampoco era tan fácil de conseguir, y como la segunda internación de los extranjeros tampoco tuvo el efecto deseado, el Cabildo pidió una medida rigurosa de la Audiencia: la internación, esta vez de todos los extranjeros, pero sin sus mujeres. Para llevarla a cabo exigía la publicación de un bando que ordenara otro registro de los extranjeros por parte de los alcaldes de barrio. El síndico del Cabildo justificó tal medida por las características de Buenos Aires de ser una ciudad grande con muchos vecinos desconocidos y, al mismo tiempo, por ser una ciudad muy abierta en la que cualquier persona podía entrar y salir sin licencia. En consecuencia, resultaba forzoso tomar medidas ya que se suponía que el enemigo estaba ante los ojos y le resultaría sencillo realizar tareas de espionaje en la ciudad y sembrar discordia entre sus filas ${ }^{112}$. Parece que las características de una ciudad portuaria como Buenos Aires con un número tan crecido de extranjeros que continuamente estaban llegando imposibilitaron lo que era el eje del régimen migratorio en la América española: la constitución de la comunidad por los propios vecinos quienes incluían a los integrados y vigilaban a los ajenos. Ante la quiebra de la vigilancia informal por los vecinos hacían falta mecanismos de control institucionalizados.

La Audiencia cedió ante la presión del Cabildo y el 3 de abril publicó un bando que anunció un nuevo sistema de registro que casi íntegramente se basaba en lo propuesto por el síndico del Cabildo. El registro de los extranjeros por los alcaldes de barrio había sido en 1804 la mayor innovación en las medidas para controlar a los extranjeros. Con este instrumento, la administración ya no dependía únicamente de la voluntad de los extranjeros de presentarse, o de las denuncias de sus vecinos, sino que se contaba con encargados propios que vigilaban los barrios y siguieron registrando en forma periódica. No obstante, la expulsión del año 1805 había demostrado también las deficiencias del sistema. La nueva herramienta para el registro que el Cabildo presentó a la Audiencia intentó remediarlas. La innovación decisiva en comparación con los registros anteriores es una combinación del control por los alcaldes de barrio con el control vecinal. El bando preveía que todos los vecinos dieran constancia de los extranjeros que vivían en sus casas ante los alcaldes de barrio. Si entraba un extranjero nuevo en alguna casa había que registrarlo igualmente, así como

\footnotetext{
111 Ibidem: 247-248.

112 Acuerdos del Extinguido..., 1926: 493- 494.
} 
también si fuera solamente un viajero que estaba de paso en la ciudad incluso cuando estos decían ser españoles. Los alcaldes de barrio fueron los encargados de coleccionar los datos en forma regular y dar cuenta una vez por semana al gobierno sobre los viajeros españoles que se hallaban en la ciudad, así como del arribo de un extranjero dentro de las primeras 24 horas ${ }^{113}$.

Era un nuevo intento por conseguir una ininterrumpida vigilancia hacia los extranjeros. Con la obligación para los dueños de casa de dejar constancia sobre los inquilinos extranjeros, y los alcaldes de barrio que vigilaban sobre el cumplimiento de la norma, el gobierno podía esperar conseguir una información bastante completa acerca de los extranjeros residentes en la ciudad que, además, se actualizaba continuamente. Teóricamente ya no era posible escapar de la expulsión por el cambio de barrio, ya que en el nuevo barrio enseguida el fugitivo hubiera sido anotado. La única manera de escapar era abandonar la ciudad, y con este camino las autoridades municipales estaban probablemente de acuerdo. Un indicio de que el sistema de control funcionaba son los pequeños informes que los alcaldes de barrio mandaban al gobierno. Estos demuestran que, al menos por un tiempo, los alcaldes de barrio registraron los cambios en relación a la presencia extranjera en sus distritos y que esta información llegó al gobierno ${ }^{114}$. Con el registro del 3 de abril el control de la población extranjera -por lo menos teóricamente, según lo previsto por el bando- se habían transformado en una práctica institucionalizada. En vez de tematizar a los extranjeros solamente en casos de conflicto, ahora se concebía la vigilancia como permanente y sistemática, obligando a los vecinos a realizar las denuncias.

En las disposiciones del bando del 3 de abril la Audiencia solamente difirió en un punto, pequeño, pero quizá decisivo, de lo propuesto por el Cabildo, porque «la circunstancia de que los alcaldes de barrio den cuenta a cualquiera de los juzgados, respecto de que deberían hacerlo precisa y únicamente a el gobierno» ${ }^{115}$. Con esto la Audiencia se reservaba el control sobre el procedimiento, el cual de otra forma hubiera podido ser fácilmente usurpado por los jueces de primera instancia, los alcaldes ordinarios del Cabildo. Quien tenía la información en sus manos también podía influir en la decisión ${ }^{116}$. La

113 AGNA, Bandos, libro 8, fols. 308-309. "Expediente obrado a representación del il. Cabildo de esta capital solicitando se publique el vando que pretende el síndico procurador general en su pedimento que acompaña", Documentos para la Hist..., 1919: 255-256.

114 Ibidem: 258-269.

115 Ibidem: 255-256.

116 La importancia de tener los informes en sus manos demuestra una carta anónima escrita el 6 de diciembre de 1809 desde Buenos Aires a la princesa Carlota, donde un anónimo relata sobre la comisión para la expulsión de extranjeros, instituida previamente, que el comisionado, 
información que llegó al gobierno no era tan sistemática y completa como el padrón de 1804, y difícilmente hubiera podido servir como base para una expulsión según los criterios establecidos por el ex-virrey Sobremonte. Pero los datos obtenidos servían a los intereses del Cabildo porque le bastaba tener información acerca de la nacionalidad y el domicilio de los extranjeros para proceder hacia una expulsión generalizada. Afortunadamente para los extranjeros, la decisión no estaba en manos de aquel sino en las de la Audiencia, cuyo objetivo era controlar a dicha población y averiguar si suponía un peligro.

El registro continuo de extranjeros no debió haber funcionado durante mucho tiempo, como mucho permaneció hasta el segundo ataque británico a Buenos Aires en julio de 1807. Después de la fracasada invasión, los ingleses, angloamericanos y otros extranjeros de sospechosa procedencia fueron objeto de la ira del Cabildo. Fue otra vez el síndico quien exigió su expulsión de Buenos Aires y Montevideo. Amenazó con apelar al Rey contra su ilegal tolerancia, si el gobierno virreinal no le hiciera caso. El Cabildo, como en las ocasiones anteriores, apoyó su demanda «teniendo al mismo tiempo presente los gravísimos males que ha causado la concurrencia de esa clase de extranjeros, la cual debe por todos motivos evitarse, y hoy con más razón por las circunstancias que han ocurrido, y están a la vista». Esta petición se mandó al gobierno "apoyándola con oficio bastante enérgico» ${ }^{117}$.

En el fondo de esta petición desairada yacía el miedo de una tercera invasión inglesa. Por la fuga de la corte portuguesa a Río de Janeiro se temía que los británicos pudieran juntarse con los portugueses para un posible ataque. Estas noticias cursaban en el pueblo y fueron influenciadas por las maniobras de la princesa Carlota, quien desde Rio de Janeiro intentó ganar partidarios para sus reclamos al trono de España también en Buenos Aires ${ }^{118}$. Pero más que el miedo por una tercera invasión, fue la figura del nuevo virrey provisional Santiago Liniers la cual provocó las enérgicas protestas del Cabildo.

Liniers se enfrentó con el problema de que las finanzas del virreinato estaban deterioradas. Los ingresos del puerto y el comercio con neutrales eran necesidades vitales para el gobierno y, por lo tanto, el virrey no tuvo ningún interés en echar a los comerciantes extranjeros ${ }^{119}$. Esto estaba en concordancia con la política de los virreyes anteriores, aunque Liniers tenía dos razones más

\footnotetext{
José Manuel de Reyes, «se alla con una lista de todos los extrangeros en esta ciudad, y todos con sus notas, y se hará cargo que todas serán malas, pues son dadas por el Cabildo. [...] Se desconfía que Alzaga es el de las notas a los portugueses, y creo no falla», Mayo documental, 1964, número 1243: 180.

117 Acuerdos del Extinguido..., 1926: 675.

118 Levene, 1941: 435-450.

119 Tjarks y Vidaurreta, 1962: 5 y 16.
} 
que le empujaron a una política tolerante hacia los extranjeros, y le apartaron de la práctica de acatar pero no cumplir la ley (algo que sus antecesores sí habían observado). Primero, Liniers -como probablemente muchos funcionarios de Buenos Aires- colaboró con los contrabandistas, sacando el mismo provecho de la presencia de los comerciantes portugueses en el puerto ${ }^{120}$. Segundo, él era francés y había llegado como extranjero a España. En 1795 uno de sus colaboradores cercanos, el también francés Carlos José Bloud, estuvo preso por la supuesta conspiración de los franceses. Contra Liniers mismo, aunque no se le acusó de nada, se habían publicado pasquines anónimos difamatorios que cuestionaban su lealtad con el Rey de España ${ }^{121}$. Quizá fue por esta experiencia que dictó un bando al estallar la guerra entre Francia y España en 1808 que llamó a la población a respetar a los franceses y sus bienes a pesar de la guerra. En este bando manifestó como principios la tolerancia y la humanidad frente a los extranjeros, con lo cual Liniers desobedeció claramente el tenor de las Leyes de Indias contra aquellos ${ }^{122}$.

El virrey no actuó contra los extranjeros ${ }^{123}$ y se mostró sordo ante las repetidas y cada vez más airadas protestas del Cabildo, cuyo hombre fuerte por aquellos años fue Martín de Alzaga, representante más influyente de los grandes mercaderes y, por lo tanto, adversario a cualquier intento de liberalización comercial. Además, desde la supuesta conspiración de los franceses en 1795, fue enemigo predilecto de Liniers ${ }^{124}$. Bajo la influencia de los monopolistas el Cabildo no dejó de presionar al virrey, instrumentalizando nuevamente la opinión pública. Avisó que los vecinos estaban muy indignados respecto a que los extranjeros se movieran libremente por la ciudad ${ }^{125}$. Como Liniers no reaccionó, el Cabildo apeló directamente al Consejo de Indias, donde una de las protestas contra el gobierno de Liniers fue la tolerancia con la que había permitido la inmigración de todos los extranjeros que querían venir al Río de la Plata ${ }^{126}$.

120 Vázquez-Rial, 2012: 106.

121 Ortega, 1947: 100-106. Vázquez-Rial, 2012: 145.

122 AGNA, Bandos, libro 8, fols. 344-345.

${ }^{123}$ No se conoce ningún bando de expulsión durante el gobierno de Liniers, no obstante sí existía con el oidor Velasco un comisionado para la expulsión de extranjeros. Probablemente el comisionado solamente consideró casos sueltos que llegaron mediante la denuncia a la Audiencia, como el caso de Nicolás Yaton, quien fue denunciado en 1807 en San Juan de ser protestante, AGNA, IX, 32-7-2, fol. 783r.

124 Sobre Alzaga véase: Lozier Almazán, 1998. Su conflicto con Alzaga: Johnson, 2013: 230 y 236.

${ }_{125}$ Acuerdos del Extinguido..., 1927: 16-17.

126 Documento 6, informe del Cabildo para el Consejo de Indias, en: Franco, 1929: 39. 


\section{El registro clandestino de 1809}

Las continuas críticas del Cabildo contra Liniers y las sospechas que cayeron sobre él, siendo francés, por la guerra contra Napoleón, llevaron finalmente a su destitución. Con su sucesor Baltasar Hidalgo de Cisneros parecía gobernar un virrey que aceptaba las demandas del Cabildo contra los extranjeros, o más bien, según los informes que el británico Alexander Mckinnon mandó a su gobierno, fue un instrumento en manos de los monopolistas que dominaban el Cabildo y el Consulado, desde donde se había promovido la destitución de Liniers. El nuevo virrey, que no tenía ninguna base de poder en la capital, dependía fuertemente del apoyo y de las influencias de los comerciantes locales $^{127}$. Así que no es sorprendente que solamente cinco días después de su toma de posición, el 3 de agosto, diera en un oficio reservado la orden de que se registrasen todos los extranjeros residentes en la ciudad. Para tal propósito convocó a los alcaldes de barrio en la sala capitular de la casa del Cabildo, donde recibieron la instrucción verbal por parte de los alcaldes ordinarios de llevar a cabo un registro clandestino ${ }^{128}$. El protagonismo del Cabildo era ya casi total. Fueron los alcaldes ordinarios quienes instruyeron a los alcaldes de barrio, así como quienes recibirían a partir de ahora los informes correspondientes. Al virrey le restaba solo dar la orden porque, dado que era de su competencia. Las listas que fueron entregadas por los alcaldes de barrio contienen, un total de 376 nombres, pero la información sobre cada uno de los extranjeros es muy fragmentaria. Debido a la clandestinidad del procedimiento no les fue posible averiguar mucho, a veces faltaba hasta el nombre o el apellido de un sujeto. Como probablemente no se daban criterios para el registro, los datos además, no son uniformes y varían mucho en su contenido. En agosto, los alcaldes ordinarios entregaron la carpeta con las listas de los alcaldes de barrio al virrey ${ }^{129}$. La decisión final sobre el procedimiento contra los extranjeros aún estaba en manos de Cisneros, pero la base para la decisión, el registro de los alcaldes de barrio, fue confeccionado por el Cabildo ${ }^{130}$.

¿Por qué el registro se tornó una práctica clandestina, diferenciándose completamente de los registros y edictos de expulsión anteriores? Quizá el Cabildo, que estuvo detrás de esta medida, sacó la conclusión de las experiencias anteriores de que actuar en secreto era mucho más eficaz. Probablemente

\footnotetext{
127 Alejandro Mackinnon y la Junta de Mayo, 1942: 16-17.

128 Acuerdos del Extinguido..., 1927: 546-547.

129 Documentos para la Hist..., 1919: 270-304 y 556-557. Véase para el registro de 1809 además: Tejerina, 2009: 27-38.

${ }^{130}$ Véase nota 114.
} 
la colaboración de la población en la detección de extranjeros mediante la denuncia era casi nula, así que tampoco había que anunciar el registro. Para asegurar que ningún extranjero lo evitara para salvarse de la expulsión, escondiéndose en la ciudad o yéndose para el interior era mejor no comunicarles las maniobras que estaban en marcha contra su presencia. Así era posible sorprenderlos y privarlos de cualquier posibilidad de reacción. Otra motivo posible para que se mantuviera en secreto el procedimiento fue la controversia en torno a la política migratoria en la ciudad. Cuando Cisneros llegó, encontró Buenos Aires dividido en dos facciones, los europeos con el Cabildo y los monopolistas por un lado, y aquellos que habían apoyado a Liniers: los cuerpos urbanos, los hacendados criollos, la Audiencia, y el obispo ${ }^{131}$. El primero de los dos partidos exigía la expulsión de los extranjeros porque el contrabando y la presencia de los comerciantes ingleses perjudicaban sus intereses económicos. El segundo grupo en el que dominaban los hacendados prefería la apertura del mercado. La presencia de los británicos era favorable para ellos porque prometían una salida para sus productos ${ }^{132}$. El virrey no pretendía convertirse en un móvil de los monopolistas, más bien su objetivo principal era «conseguir la reconciliación, unión devida y necesaria» entre los dos partidos ${ }^{133}$. Quizá para complacer al Cabildo y a los monopolistas cedió a su petición de un registro de los extranjeros, pero para no ahondar la brecha entre los dos partidos no quiso que tal medida se hiciera pública.

Finalmente hubo un cambio de rumbo de la política económica en Buenos Aires. A lo largo del año 1809 la mayor parte de la Junta de Gobierno, convocada por Cisneros, se inclinó a favor del comercio libre que se decretó en noviembre de $1809^{134}$. Como no podían deshacer la apertura del comercio con los ingleses, los monopolistas intentaron atacar a sus adversarios librecambistas por otro frente, exigiendo nuevamente la expulsión de los extranjeros, sobre todo de los ingleses ${ }^{135}$. Cisneros cedió antes sus reclamos y tomó medidas contra la presencia prolongada los comerciantes británicos en el puerto. Además decretó una medida drástica que ya no parecía en uso y que, probablemente, nunca se había aplicado al pie de la letra: la expulsión general sin admitir excepciones. Sin publicar un bando al respecto mandó en diciembre de 1809 expulsar a los portugueses porque eran sospechosos de apoyar las pretensiones

131 Colomer Pellicer, 1997: 486.

132 Schlez, 2010: 123-124. Sobre el peso de los hacendados en el Cuerpo de Patricios: Harari, 2006: 142-144.

133 "Carta de Cisneros a Martín de Garay”, Mayo documental, 1961, número 1141: 263.

134 Tjarks, 1957, vol. 1: 349-353.

135 Tjarks, 1961: 51. 
de la princesa Carlota en Río de Janeiro, y a los franceses que, debido a la guerra contra Napoleón, otra vez se habían convertido en enemigos ${ }^{136}$. Para efectuar la expulsión de los extranjeros no deseados se instaló una comisión al mando del oidor de la Audiencia José Manuel de Reyes a cuyas órdenes trabajaban los alcaldes de barrio y los de la Hermandad ${ }^{137}$. La comisión no consiguió terminar su labor. Cuando el 18 de mayo de 1810 se hizo pública en Buenos Aires la caída de la Junta suprema, la expulsión de los extranjeros para la península carecía ya de fundamentos. El 21 de mayo Reyes pidió al virrey ser eximido de su comisión, una petición a la que correspondió la Junta provisional gubernativa el día 13 de junio ${ }^{138}$.

\section{Conclusiones}

En la percepción y el trato de los extranjeros se puede observar una gran diferencia entre el campaña de Buenos Aires y las provincias del interior por un lado, y las ciudades Buenos Aires y Montevideo, y la campaña de la banda oriental por el otro. En la campaña de Buenos Aires parece que no se percibían a los extranjeros como tales, por lo menos en los registros la naturaleza de un individuo (su lugar de origen) simplemente no importaba, y se incluían a los extranjeros entre los españoles. La única diferencia que se aplicaba era entre vecino (casado en el lugar) y forastero. Esta diferenciación si importaba, porque quien vivía sin pertenencia local era peligroso ${ }^{139}$. Allí y en las provincias del interior casi no se han trasmitido conflictos entre naturales y extranjeros donde la condición de estos últimos hubiera importado. Aquellos gobernadores a los que fue encargado el registro de la población extranjera y la fabricación de expedientes en muchos casos defendieron decididamente a los extranjeros de sus distritos. No se conoce ningún caso donde un extranjero fuera expulsado.

En Buenos Aires, y, en menor medida, también en Montevideo (y de los territorios de la banda oriental), en cambio, surgieron conflictos entre naturales y extranjeros, dado que por la cercanía de Brasil y su condición de ciudades

136 Para la política de Cisneros contra británicos y portugueses véase: Colomer Pellicer, 1997: 470 y 486-487 y contra los portugueses: Tejerina, 2009: 27-60. La expulsión generalizada y sin exepción de los franceses se encuentra en un oficio del 8 de enero de 1810, AGNA, X, Sección facticia Archivo del Gobierno de Buenos Aires, XXXVII, 17. La de los portugueses se puede deducir de la ya citada carta anónima que informó la princesa Carlota al respecto. Mayo documental, 1964, número 1243: 180.

${ }_{137}$ AGNA, X, Sección facticia Archivo del Gobierno de Buenos Aires, CXXIV, 5 y XXI, 1.

138 AGNA, X, Sección facticia Archivo del Gobierno de Buenos Aires, XXXVII, 75.

139 Véase: Herzog, 2010: 169. 
portuarias allí se hicieron patentes el miedo a una invasión extranjera y los intereses económicos de los grandes comerciantes ultramarinos contra sus competidores extranjeros. El Cabildo de Buenos Aires tenía mucho protagonismo en los procesos de su regulación, ya que consideró los asuntos de pertenecía a la comunidad como suya, con lo cual quería tomar también la decisión respecto a quienes de los extranjeros podían ser tolerados siendo vecinos. Esta aspiración fue una fuente de conflictos con los gobernadores y virreyes, cuando estos defendían la prerrogativa Real en el régimen migratorio. Esta situación se agravó con Sobremonte quien, como representante del reformismo borbónico, pretendió reducir la autoridad municipal y confrontó al Cabildo. No fue, por eso, solamente por los intereses económicos de la élite capitular o por cuestiones de seguridad, sino también en su lucha por el poder en la ciudad que el Cabildo criticó la presencia en contra de las leyes de tantos extranjeros. Fue un arma para reclamar competencia en el régimen migratorio y criticar al gobierno superior con protestas que fueron elevados hasta ante el rey. La Corona, en vez de apoyar a los que velaron por su autoridad, solió favorecer a las élites locales en contra de los virreyes. Sobremonte lo vio muy claro al criticar que «en la Corte se miran [...] con más consideración sus representaciones que la de estos Jefes autorizados $\gg{ }^{140}$.

El protagonismo de los vecinos en el régimen migratorio se manifestaba en la denuncia de conflictos con los extranjeros y la identificación de quienes los causaron. A lo largo de los años se puede observar cierta evolución y un paulatino cambio de un control vecinal informal de los extranjeros, donde las autoridades solo actuaron en casos de denuncia y conflicto, hacia una mayor participación de las instituciones de gobierno con una formalización y perpetuación del control. Este cambio iba aparejado con una creciente desconfianza hacia la colaboración de los vecinos. El primer intento para intensificar el control fue el empleo de castigos para quienes no colaboraran. Los bandos de los años 30 se limitaban a anunciar la expulsión de los extranjeros contenidos en una lista y se amenazaba con una penalización cada vez más severa para quienes permanecieran: desde el secuestro de bienes, el trabajo forzoso en la fortaleza de Montevideo o el destierro a Perú, hasta 200 azotes públicos y diez años de galera, castigos que probablemente nunca se pensaba aplicar. Con el tiempo las sanciones no se limitaron a los extranjeros, sino finalmente incluyeron también

${ }^{140}$ Valle, 2005: 82-83. Como la Corona no estaba dispuesta a confrontarse con las élites locales para imponer su autoridad, el pacto entre entre la Corona y élite capitular de Buenos Aires quedó intacto hasta el final de la época colonial. Valle, 2014: 231-232. Para John Lynch el «consensus colonial» termina con el reformismo de Carlos III cuyo propósito era restablecer la autoridad real y controlar los recursos americanos. Lynch, 1992: 77. 
a los vecinos que les dieron protección. Por la escasez de denuncias vecinales que conocemos, parece que estos no apoyaron las pretensiones ni del Cabildo ni del gobierno superior o de la Audiencia, más bien por el contrario, tendían a cubrir a los extranjeros con quienes convivían, trabajaban, o negociaban. Para hacer más eficaz sus medidas les era imprescindible al gobierno contar con un aparato de control, por más rudimentario que sea: los alcaldes de barrio. La gran ventaja de su protagonismo es que ahora, supuestamente, se conseguirían los datos de todos los extranjeros en la ciudad, cuando antes, con las denuncias o los bandos que convocaban a los extranjeros al registro, estos datos eran muy parciales y abiertos a la evasión. En este proceso la clandestinidad del registro secreto de los extranjeros en 1809 es el punto final de un continuo proceso en el que la población ya no tenía ningún protagonismo. No solamente ya no se necesitaba al vecino para controlar el cumplimiento de lo dictado, sino que ahora podía incluso estorbar su aplicación.

Al final de la época colonial aparecieron comisiones a las que el virrey encargó el registro y la expulsión de los extranjeros. Las comisiones que ordenaron los registros pretendían obtener una información uniforme y conmensurable que se basaba en criterios generales, en cuya fijación y aplicación pusieron mucho empeño. Esta práctica tendía a la abstracción del registro, favoreciendo el uso de listas, palabras claves, y, sobre todo, tablas. Una consecuencia de estas paper technologies del siglo XVIII es dejar la singularidad de casos concretos y modificar estos según los criterios generales para mejorar su uso ${ }^{141}$. Con la información obtenida por criterios y fijada en tablas o listas, la decisión sobre los extranjeros tendía a desindividualizarse. Ya no eran personas con un currículo individual y con características particulares, sino nombres a los que se le cruzaron algunos datos en los que finalmente se habría de basar la decisión sobre la permanencia del extranjero. Su expulsión era más probable si de ellos se disponía solamente de los datos parcos de una tabla o lista, porque en este caso la comisión podía tomar la decisión únicamente en base a los criterios previamente establecidos y no quedaba margen de maniobra por razones individuales. Además, una tabla carecía de cualquier mensaje emocional.

Este paulatino cambio en el registro correspondía al uso que los jueces de la Audiencia querían hacer de los datos. Velaron, dentro de sus posibilidades y límites, por una aplicación rígida de la ley. Esta se aseguró mediante el empleo de criterios para la tolerancia de los extranjeros que habían emanado

${ }^{141}$ Es una tendencia que no se observa solamente en el registro de la población, sino que estaba bastante generalizada a lo largo del siglo XVIII. Por ejemplo se aplica también a la descripción de enfermedades, véase: Hess y Mendelsohn, 2013: 76-77. 
de las leyes. Gobernar -en este caso regular la presencia de los extranjerospara jueces como Márquez de la Plata era tomar decisiones en forma objetiva, abstracta, legal, según los criterios previamente establecidos, sin miramientos a los casos individuales y basada en las leyes como única normativa. Con esto se apartaron de lo habitual en las comunidades en Hispanoamérica, donde la integración y, por lo tanto, aceptación de los extranjeros era una práctica social de facto que correspondía a los vecinos, pero no un proceso legal en manos de las instituciones gubernamentales.

A finales de la época colonial ciertos actores, sobre todo los juristas de la Audiencia y del Cabildo, anticiparon un procedimiento típico solo para el régimen migratorio del Estado burocrático moderno con su tendencia a la abstracción y despersonalización de la administración, con su necesidad de un aparato policial para asegurar el dominio de la ley, y con el registro de la población estandarizado, convirtiendo el control esporádico de los extranjeros en caso de conflictos en una vigilancia permanente ${ }^{142}$. Tal planteamiento existía, por lo menos, conceptualmente, y los comisionados debían haber percibido la necesidad de llevarlo a cabo, pero hasta el final de la época colonial un procedimiento tan institucionalizado no era posible, ya que la realidad en Buenos Aires a principios del siglo XIX no fue ni tan burocrática ni tan distante y abstracta como la que unos cien años más tarde describió Franz Kafka en Das Schloss. Como a estas alturas en Hispanoamérica aún no existía una policía profesional e institucionalizada como, por ejemplo, la que se había creado en París, la implementación de las normas dependía de los alcaldes de barrio. Pero estos seguían siendo vecinos y su cumplimiento de lo dictado por el gobierno poco fiable. Además, tanto los alcaldes de barrio como el gobierno superior no solían desoír las peticiones que recibían por parte de los extranjeros en peligro de expulsión. Así quedaba abierta una puerta para el trato personal y la negociación entre gobierno y gobernados que hacía menos probable la expulsión de un extranjero, ya que, como alega Tamar Herzog, era mucho más difícil expulsar a un individuo concreto que a un extranjero abstracto. Tampoco hay que olvidar que el procedimiento burocrático según criterios trajo también ciertas ventajas. La denuncia era algo muy personal y dependía del conocimiento personalizado entre individuos, pero a la vez podía ser algo muy cruel que dejaba en una situación bastante precaria al extranjero. Una decisión según criterios era mucho más objetiva y y las animosidades personales quedaban excluidas.

Finalmente, a pesar de la frialdad del procedimiento burocrático, y de los continuos intentos por registrar a todos los extranjeros, el Cabildo no consiguió

142 Véase: Weber, 1967: 125. 
su propósito de echarlos. Quizá, porque faltaba una policía capaz de controlar con más eficacia la ciudad, quizá porque faltaron barcos para transportarlos a Europa, quizá también, porque en la población no había mucha voluntad de echar a los extranjeros que eran sus vecinos pero, sobre todo, probablemente, porque el gobierno superior de los virreyes no tenía ningún interés en su expulsión. Reservas legales, aversiones políticas y personales con el Cabildo, escrúpulos humanos y claros intereses económicos debieron haber influido en socavar cualquier intento de expulsión.

\section{Bibliografía}

Acuerdos del Extinguido Cabildo de Buenos Aires, 47 vols., Buenos Aires, Tall. Gráf. de la Penitenciaría Nacional, 1907-1934.

Alejandro Mackinnon y la Junta de Mayo, Núcleo Argentino de estudios Históricos (ed.), Buenos Aires, Multi-Revista, 1942.

Archivo General de la República Argentina. Periodo colonial. Año 1806. Invasiones inglesas, segunda serie, vol. XII, Adolfo P. Carranza (ed.), Buenos Aires, Kraft, 1889.

Brading, David, "La España de los Borbones y su imperio americano", Leslie Bethell (ed.), Historia de America latina, vol. 2. América colonial: Europa y América en los siglos XVI, XVII y XVIII, Barcelona, Crítica, 1990: 85-126.

Brown, Jonathan, Historia socioeconómica de la Argentina. 1776-1860, edición en castellano de la primera edición en ingles 1979, Buenos Aires, Siglo XXI, 2002.

Campbell, Leon G., "The Foreigners in Peruvian Society during the Eighteenth Century", Revista de Historia de América, 73/74 (México, 1972): 153-163.

Colomer Pellicer, Francisca, Baltasar Hidalgo de Cisneros. Último Virrey del Virreinato del Río de la Plata, Una biografía histórica, tesis doctoral, Universidad de Murcia, 1997.

De Studer, Elena F. S., La trata de negros en el Río de la Plata durante el siglo XVIII, Buenos Aires, Departamento Editorial, 1958.

Documentos para la Historia Argentina, vol. 5. Comercio de Indias. Antecedentes Legales (1713-1778), Facultad de Filosofía y Letras (ed.), Buenos Aires, Peuser, 1915.

Documentos para la Historia Argentina, vol. 12. Territorio y población, Facultad de Filosofía y Letras (ed.), Buenos Aires, Peuser, 1919.

Enríquez Macías, Genoveva, "Franceses en América: la Revolución al otro lado del Atlántico", Emilio de Diego García (ed.), Repercusiones de la Revolución Francesa en España, Madrid, Universidad Complutense, 1990: 715-728. 
Franco, José R. de, Preliminares de la Revolución de Mayo. El Cabildo y los Virreyes, Buenos Aires, Academia Americana de Historia, 1929.

García Estrada, Rodrigo de J., La condición de extranjero en el tránsito de la Colonia a la República en la Nueva Granada, 1750-1830, tesis doctoral, Universidad Andina Simón Bolívar, Medellín, 2012.

Gómez Pérez, Carmen, "Los extranjeros en la América colonial: su expulsión de Cartagena de Indias en 1750", Anuario de Estudios Americanos, 37 (Sevilla, 1980): 279-311.

González Beltrán, Jesús Manuel, "Legislación sobre extranjeros a finales del siglo XVIII", Trocadero, 8-9 (Cádiz, 1997): 103-118.

Guerra, François-Xavier, “'Voces del pueblo'. Redes de comunicación y orígenes de la opinión en el mundo hispánico (1808-1814)", Revista de Indias, 62 (Madrid, 2002): 357-384.

Harari, Fabian, “¿Ampliación política o crisis orgánica? Un análisis del Cuerpo de Patrícios, 1806-1810", Anuario del Instituto de Historia Argentina, 6 (La Plata, 2006): 125-145.

Herzog, Tamar, “'A Stranger in a Strange Land': The Conversion of Foreigners into Community Members in Colonial Latin America (17th-18th Centuries)", Social Identities, 3 (London, 1997): 247-264.

Herzog, Tamar, Defining Nations. Immigrants and Citizens in Early Modern Spain and Spanish America, New Haven, Yale University Press, 2003.

Herzog, Tamar, "Nosotros y ellos: españoles, americanos y extranjeros en Buenos Aires a finales de la época colonial", José I. Fortea y Juan E. Gelabert (eds.), Ciudades en conflicto (siglos XVI-XVIII), Madrid, Marcial Pons Historia, 2006: 241-257.

Herzog, Tamar, "Ciudad y ciudadanía en el mundo hispano y atlántico", Anuario IEHS, 25 (Buenos Aires, 2010): 167-177.

Herzog, Tamar, "Naturales y extranjeros: sobre la construcción de categorías en el mundo hispánico", Cuadernos de Historia Moderna, 10 (Madrid, 2011): 21-31.

Hess, Volker y Mendelsohn, J. Andrew, "Paper Technology und Wissensgeschichte", Zeitschrift für Geschichte der Wissenschaft, Technik und Medizin, 21 (Basilea, 2013): 1-10.

Johnson, Lyman L., "Juan Barbarin: The 1795 Conspiracy in Buenos Aires", Kenneth Andrien (ed.), The Human Tradition in Colonial Latin America, Wilmington, Scholarly Resources, 2002: 259-277.

Johnson, Lyman L., Los talleres de la revolución. La Buenos Aires plebeya y el mundo del Atlántico, 1776-1810, Buenos Aires, Prometeo Libros, 2013.

Konetzke, Richard, "Legislación sobre inmigración de extranjeros en América durante la época colonial", Revista internacional de Sociología, 3 (Córdoba, 1945): 269-299. 
Kraselsky, Javier, Las estrategias de los actores del Río de la Plata: las Juntas y el Consulado de comercio de Buenos Aires a fines del Antiguo Régimen (1748-1809), tesis doctoral, Universidad Nacional de La Plata, 2010.

Langue, Frédérique, "Los franceses en Nueva España a finales del siglo XVIII. Notas sobre un estado de opinión", Anuario de Estudios Americanos, 46 (Sevilla, 1989): 219-241.

Levene, Ricardo, "Intentos de independencia en el Virreinato del Río de la Plata (1781-1809)", Ricardo R. Caillet-Bois (ed.), Historia de la Nación Argentina, vol. 5. La Revolución de Mayo hasta la Asamblea General Constituyente, segunda edición, Buenos Aires, El Ateneo, 1941: 423-467.

Lewin, Boleslao, "La conspiración de los franceses en Buenos Aires (1975)", Anuario del Instituto de Investigaciones Históricas de Rosario, 4 (Rosario, 1960): 9-57.

Lewis, James, "Anglo-American Entrepreneurs in Havanna: the Backround and Significance of the Expulsion of 1784-1785", Jaques A. Barbier y Kuethe (ed.), The North American Role in Spanish Imperial Economy. 1760-1819, Manchester, University Press, 1984: 112-126.

Lozier Almazán, Bernardo, Martín de Alzaga. Historia de una trágica ambición, Buenos Aires, Ediciones Ciudad, 1998.

Lynch, John, "Intendants and Cabildos in the Viceroyalty of the La Plata", The Hispanic American Historical Review, 35 (Durham, 1955): 337-362.

Lynch, John, "The Institutional Framework of Colonial Spanish America", Journal of Latin American Studies, 24 (Cambridge, 1992), 69-81.

Manz, Volker, Fremde und Gemeinwohl. Integration und Ausgrenzung in Spanien im Übergang vom Ancien Regime zum frühen Nationalstaat, Stuttgart, Steiner, 2006.

Mayo documental, 12vols., Facultad de Filosofía y Letras (ed.), Buenos Aires, Kraft, 1961-65.

Munck, Bert De y Winter, Anne, "Regulating Migration in Early Modern Cities: An Introduction", Gated Communities? Regulating Migration in Early Modern Cities, Farnham, Ashgate, 2012: 1-14.

Ortega, Exequiel César, El complot colonial, Buenos Aires, Ayacucho, 1947.

Ozanam, Didier, “Le recensement des étrangers en 1791; une source pour l'etude des colonies français en Espagne", Bartholomé Bennassar (ed.), Les français en Espagne a l'époque moderne (XVI-XVIII siècles), París, Ed. Du Centre, 1990: 215-227.

Paquette, Gabriel B., Enlightenment, Governance, and Reform in Spain and ist Empire, 1759-1808, Basingstoke, Plagrave Macmillan, 2011. 2 ${ }^{\mathrm{a}}$ ed.

Parrón Salas, Carmen, "El nacionalismo emergente y el comercio. La expulsión de extranjeros de América (Perú)", Actas del XI Congreso de la AHILA, vol. 1, Liverpool, University Press, 1998: 200-218. 
Pérez, Ana María y Montoya Guzmán, Juan David, “La invención de la población: salud y riqueza en el Nuevo Reino de Granada, 1760-1810", Secuencia, 78 (México, 2010): 15-42.

Poggio Ghilarducci, Eleonora, "Las composiciones de extranjeros en la Nueva España, 1595-1700", Los Extranjeros y la Nación en España y la América española. Cuadernos de Historia Moderna. Anejos, 10 (Madrid, 2011): 177-193.

Recio Morales, Oscar y Glesener, Thomas, “Introducción”, Cuadernos de Historia Moderna. Anejos, 10 (Madrid, 2011): 11-18.

Reitano, Emir, "Ascenso social, consolidación y prestigio. El caso de los portugueses y sus redes sociofamiliares en el Buenos Aires tardocolonial", Trabajos y Comunicaciones, 32-33 (La Plata, 2006-2007): 115-139.

Reitano, Emir, La inmigración antes de la inmigración: los portugueses de Buenos Aires en vísperas de la Revolución de Mayo, Mar de Plata, Eudem, 2010.

Rodríguez Vicente, María Encarnación, "Los extranjeros y el mar en Perú (fines del siglo XVI y comienzos del siglo XVII)", Anuario de Estudios Americanos, 25 (Sevilla, 1968): 619-629.

Rosas Lauro, Claudia, Del trono a la guillotina. El impacto de la Revolución Francesa en el Perú (1789-1808), Lima, IFEA, 2006.

Sánchez Rubio, Rocío y Testón Núñez, Isabel, “"Fingiendo llamarse ... para no ser conocido'. Cambios nominales y emigración a Indias (siglos XVI-XVIII)", Norba. Revista de Historia, 21 (Badajoz, 2008): 213-239.

Schlez, Mariano, "El bando de los opresores. La derrota política y social de los contrarevolucionarios en Buenos Aires (1810-1816)", Historia Caribe, 16 (Barranquilla, 2010): 105-126.

Sidy, Bettina Laura, "Crecimiento urbano, necesidades y conflictos: las ordenanzas del gobierno local en torno a los extranjeros (Buenos Aires 1740-1760)", Fronteras de la Historia, 16 (Bogotá, 2011): 392-415.

Socolow, Susan, Los mercaderes del Buenos Aires virreinal: familia y comercio, Buenos Aires, Ed. de la Flor, 1991.

Solano, Sergio Paolo, “¿Cómo se construyeron los censos de población del Nuevo Reino de Granada a finales del siglo XVIII?", El Taller de la Historia, 6 (2014): $1-59$.

Tau Anzoátegui, Victor, "Una defensa de los extranjeros en el Buenos Aires de 1743”, VI Congreso Internacional de Historia de América, vol. 6, Buenos Aires, Academia Nacional de la Historia, 1982: 276-279.

Tau Anzoátegui, Victor, Casuismo y sistema. Indagación histórica sobre el espíritu del derecho indiano, Buenos Aires, Instituto de Investigaciones de Historia del Derecho, 1992. 
Tejerina, Marcela Viviana, "Extranjeros en el Río de la Plata a principios del siglo XIX: aspectos jurídicos-políticos de su participación en el ámbito militar”, Revista de Historia de América, 122 (México, 1997): 139.

Tejerina, Marcela Viviana, Luso-Brasileños en el Buenos Aires virreinal. Trabajo, negocios e intereses en la plaza naviera e comercial, Bahía Blanca, Universidad Nacional del Sur, 2004.

Tejerina, Marcela Viviana, "Frontera e inmigración en épocas de revolución: la situación de los portugueses en el Río de la Plata", Nuevo Mundo Mundos Nuevos (Paris, 2009): http://nuevomundo.revues.org/53842.

Tejerina, Marcela Viviana, "De la internación a la colonización: el extranjero como agente poblador de los Borbones en el Río de la Plata", Marcela Viviana Tejerina (ed.), Definir al otro: el Río de la Plata en tiempos de cambio (1776-1820), Bahía Blanca, Ed. de la Universidad Nacional del Sur, 2012: 49-77.

Tjarks, Germán O. E., El Consulado de Buenos Aires y sus proyecciones en la historia del Río de la Plata, 2 vols., Buenos Aires, Universidad, 1957.

Tjarks, German O. E. y Vidaurreta, Alicia, El comercio inglés y el contrabando. Nuevos aspectos en el estudio de la política económica en el Río de la Plata (1807-1810), Buenos Aires, Matera, 1962.

Torpey, John, Invention of the Passport. Surveillance, Citizenship and the State, Cambridge, University Press, 2000.

Torre Revello, José, El marqués de Sobre Monte. Gobernador intendente de Córdoba y virrey del Río de la Plata. Ensayo histórico, Buenos Aires, Peuser, 1946.

Valle, Laura Cristina del, "Rasgos de identidad y discurso identitario: algunas reflexiones sobre la élite capitular de Buenos Aires (1776-1810)", Christian Büschges y Frédérique Langue (eds.), Excluir para ser: procesos identitarios y fronteras sociales en la América hispánica (siglos XVII-XVIII), Fráncfort/Madrid, Vervuert/ Iberoamericana, 2005: 81-98.

Valle, Laura Cristina del, "Geografía política y espacios de poder: acciones y reacciones del Cabildo porteño en la época tardocolonial (1776-1810)", Hilda Raquel Zapico (ed.), De prácticas, comportamientos y formas de representación social en Buenos Aires (S. XVII-XIX), Bahía Blanca, Ediuns, 2006: 23-46.

Valle, Laura Cristina del, Los hijos del poder. De la élite capitular a la Revolución de Mayo. Buenos Aires 1776-1810, Buenos Aires, Prometeo Libros, 2014.

Vázquez-Rial, Horacio, Santiago de Liniers, Madrid, Encuentro, 2012.

Weber, Max, Rechtssoziologie, Berlin, Luchterhand, 1967. $2^{\mathrm{a}}$ ed.

Wolff, Frank, "Rethinking Migration Regimes: Lesson of Post-Communism", www. indiana.edu/ reeiweb/newsEvents/2013/wolff.pdf, 2013: 1-5. 
Yacou, Alain, "L'expulsion des Français de Saint-Domingue réfugiés dans la région orientale de l'île de Cuba", Cahiers du monde hispanique et luso-brésilien, 39 (Toulouse, 1982): 49-64.

Fecha de recepción: 22 de junio de 2014.

Fecha de envío de las modificaciones: 20 de noviembre de 2014.

Fecha de aceptación: 21 de noviembre de 2014.

\section{Control of foreigners in the viceroyalty of Río de la Plata (1730-1809)}

During the eighteenth century, surveillance of foreigners depended mainly on the cooperation of the neighbors who reported them. This informal vigilance, where the government only acted in case of conflict, was finally replaced by an institutionalized, clandestine and permanent control. This article is based on documentation of the Viceroyalty of Rio de la Plata, taken from published but previously unknown sources in the Archivo General de la Nación Argentina. The most relevant sources are royal decrees, edicts and government orders, the registration of foreigners, in particular, and also Cabildo proceedings.

Key words: Buenos Aires; Río de la Plata; Foreigners; eighteenth Century; Migration Regime. 